\title{
Reconfigurable Antennas and Their Applications
}

\author{
Harish Chandra Mohanta ${ }^{1,2, *}$, Abbas Z. Kouzani ${ }^{1}$, Sushanta K. Mandal ${ }^{3}$ \\ ${ }^{1}$ School of Engineering, Deakin University, Australia \\ ${ }^{2}$ Department of Electronics and Communication Engineering, Centurion University of Technology and Management, India \\ ${ }^{3}$ Department of Electronics and Communication Engineering, Sharda University, India
}

Received August 10, 2019; Revised September 12, 2019; Accepted September 21, 2019

Copyright $\odot 2019$ by authors, all rights reserved. Authors agree that this article remains permanently open access under the terms of the Creative Commons Attribution License 4.0 International License

\begin{abstract}
Reconfigurable antennas are capable of dynamically altering their frequency, polarization, and radiation properties in a controlled and reversible manner. They modify their geometry and behaviour to maximize the antenna performance in response to changes in their surrounding conditions. To implement a dynamical response, they employ different mechanisms such as PIN diodes, varactors, radio-frequency microelectromechanical systems (RF-MEMS), field effect transistors (FETs), parasitic pixel layers, photoconductive elements, mechanical actuators, metamaterials, ferrites, and liquid crystals. These mechanisms enable intentional distribution of current on the antenna surface producing reversible modification of their properties. This paper presents the design process and applications of reconfigurable antennas. The activation mechanisms of reconfigurable antennas, and their design and operation optimization are discussed. The latest advances on reconfigurable metamaterial engineering, and the current trends and future directions relating to reconfigurable antennas are reviewed. Finally, the applications of reconfigurable antennas in cognitive radio, multi-input multi-output (MIMO) systems, satellite communications, and biomedical devices are highlighted.
\end{abstract}

Keywords Radiation Pattern, Polarizations, Radio Frequency Microelectromechanical System, PIN Diodes, Varactors, Metasurface, Optical Switches, Reconfigurable Antennas

\section{Introduction}

Due to the rapid growth of wireless communications, and the high demand for the integration of multiple wireless standards into a single platform, it is highly desirable that the operating frequency, radiation pattern, and polarizations of antennas can be reconfigurable [1]. Reconfigurable antennas modify their operating frequency, impedance bandwidth, polarization, and radiation pattern as per the operating requirements of the host system. They can radiate multiple patterns at different frequencies and polarizations. Obtaining the desired functionality for a reconfigurable antenna and integrating it into a complete system to achieve an efficient and cost-effective solution is a challenging task for antenna designers.

Converting an antenna into a reconfigurable device by applying different techniques to change the antenna's internal structure has been challenging. Multiple factors need to be considered such as achieving a good gain, good efficiency, stable radiation pattern, and a good impedance match throughout all the antenna's operation states.

To achieve a good gain, stable radiation pattern, and a good impedance throughout the operation states, the reconfigurable antenna designers must focus on the following questions: (i) Which antenna property (e.g. frequency, radiation pattern, or polarization) must be modified? (ii) How are the radiating elements of the antenna structure reconfigured to achieve the required property? (iii) Which reconfiguration technique can minimize the negative effects on the antenna performances?

A reconfigurable antenna provides the same functionality as that given by multiple single-purpose antennas. This offers saving in costs, weight, volume, and maintenance/repair resources. The following subsections present the definition of the critical parameters for antenna development.

\subsection{Antenna Parameters}

Antenna parameters can be classified into four categories: physical parameters, circuit parameters, transition parameters, and space parameters. The physical parameters include size, material, temperature, wind pressure, supporting structure, and coating. The circuit parameters include input impedance, bandwidth, radiation resistance, self and mutual inductance and gain. The 
transition parameters include loss, attenuation and mismatch. Finally, the space parameters are radiation pattern shape, beam width, directivity, radiation intensity, lobes and polarizations.

The input impedance over frequency (typically called the frequency response) and the radiation (or radiation pattern) are two basic parameters which are used to characterize an antenna. The frequency response is used for the input impedance matching. Without the proper input impedance match, the transmitting system will suffer from component failure and power wastage due to severe reflections, while the receiving system will suffer from reduction in sensitivity and require additional amplification. The antenna's frequency response determines its radiation pattern.

\subsection{Frequency Response}

Frequency response is the input impedance over the frequency range. The complex input impedance can be represented as:

$$
z_{\text {in }}(\omega)=R(\omega)+j X(\omega)
$$

where $\operatorname{Zin}(\omega)$ is the complex input impedance, $R(\omega)$ is resistance, $\mathrm{X}(\omega)$ is reactance and $\omega=2 \pi f$ is the frequency in radian. The complex input impedance describes the antenna as a circuit element. The antenna's input impedance determines the reflection coefficient $(\Gamma)$, return loss (RL), VSWR (voltage standing wave ratio).

$$
\Gamma=\frac{z_{\text {in }}(\omega)-z_{0}}{Z_{\text {in }}(\omega)+z_{0}}
$$

where $Z_{\text {in }}(\omega)$ is input impedance of the antenna and $Z_{0}$ is the characteristics impedance of the transmission line. $\Gamma$ is always a negative number. We can also use $S_{11}$ to represent $\Gamma$.

$$
\text { Return Loss }=\mathrm{RL}=-20 \log \boldsymbol{\Gamma}
$$

The return loss is always a positive number. The possible values of return loss range from $0 \mathrm{~dB}$ to $\infty \mathrm{dB}$. The voltage standing wave ratio $(V S W R)$ is defined as:

$$
V S W R=\frac{V_{\max }}{V_{\min }}=\frac{1+|\Gamma|}{1-|\Gamma|}
$$

Where $\mathrm{V}_{\max }$ is the maximum voltage amplitude of the standing wave and $\mathrm{V}_{\min }$ is the minimum voltage amplitude of the standing wave. The possible VSWR values from 1 to $\infty$.

$V S W R=1$ means the transmission line is perfectly matched with antenna input impedance, and $V S W R=\infty$ means the transmission line is completely unmatched with antenna input impedance.
Over the years, antennas have been designed with input impedance $50 \Omega$ which perfectly match with $50 \Omega$ characteristics transmission line system, leads to reflection coefficient of zero, a VSWR of one and an RL of infinity. Smith chart describes about the input impedance, reflection coefficient, and frequency behaviour that may be either inductive or capacitive. Smith chart provides the information about the antenna's resonant behaviour as the antenna is resonant at frequencies at pure and convenient input impedance.

\subsection{Radiation Characteristics}

Radiation pattern is one of the most important characteristics of antennas. It is a graphical representation of antenna's far-field radiation properties. It also describes the ability of an antenna to transmit/receive signals in a direction. It can be specified by the unit decibels (dB). Polarization of an antenna's radiation pattern can be defined as the change in the electric field vector with respect to the direction of propagation. Polarization is an important parameter in an antenna. It acts as a filter for undesired signals. There are three types of polarizations which are linear, elliptical, and circular polarization [2]. In case of polarization, the antenna radiation pattern describes the fundamental shape and characteristics of the antenna. Beam width is one of the parameter which can be described in a two-dimensional plane in the radiating volume of the antenna. The half-power beam width of the antenna can be defined as the parameter which measures the angle surrounding the direction of maximum radiation. It describes the antenna's normalized radiation intensity is greater than 0.5 .

The first null beam width can be defined as it is the angle between the first pattern nulls adjacent to the main lobe of the pattern. The two parameters which are half-power beam width and full-null beam width describe the shape and the extent of the main beam of the antenna.

Directivity and gain describe the antenna efficiency. The antenna's directivity can be defined as the ratio of the radiation intensity in a given direction to the average radiation intensity in overall direction. Gain can be defined as the ratio of the radiation intensity of a test antenna in a given direction, to the radiation intensity of an isotropic antenna.

If a direction is not particularly specified for directivity or gain, the direction of the maximum radiation intensity is implied which describes the loss as the loss does not arise from the impedance and polarization mismatch. If the antenna is ideal and there is no power dissipation, then the gain and directivity of an antenna can be interchanged. Antenna efficiency is an antenna parameter which captures the antenna's losses and describes a relation related to the gain and directivity by the relation: 


$$
\mathrm{G}=\eta \mathrm{D}
$$

where $\mathrm{G}$ is the gain of an antenna is the directivity $\mathrm{D}$ of an antenna and $\eta$ is the antenna efficiency. The ohmic losses created from the imperfect conductors and dielectric determine the radiation efficiency. Basically, in a reconfigurable antenna, these losses can be arisen. There is a possibility of other types of issues imposed by solid-state devices such as diodes, field-effect transistors (FETs), plasma-based devices, switches, or materials used to enable reconfiguration. Frequency reconfigurability can be achieved by controlled changes in the dielectric, or magnetic changes in the materials such as ferroelectrics and ferrites.

As we deal with electro-magnetic waves, the antenna acts as a transducer between guided and unguided electromagnetic wave. The antenna is part of a circuit which behaves as a radiator. Reconfigurability is a property where the frequency response, will have an impact on radiation characteristics. In the same way, reconfigurations that result in radiation pattern changes will also alter the antenna's frequency response. The reconfigurable antenna developers prefer the characteristics to be separable which is a major challenge for them. Metamaterial will provide miniaturization of the antenna with desired frequency along with specific absorption rate (SAR) reduction [93]-[94].The miniaturization of constitutive elements of metasurface allows more fine control of the desired distribution of the electromagnetic fields [96].

The special type of metamaterial based reconfigurable antenna can be used for military as well as biomedical device sectors with the following desirable characteristics (i) compact size, (ii) low profile, (iii) conformal, (iv) multi band or broad band, (v) low frequency, and (vi) low specific absorption rate (SAR).

Using a reconfigurable metamaterial antenna, we can develop a compact frequency and pattern reconfigurable rectenna for wireless powering of medical devices.

In this paper, the classification of reconfigurable antennas, their reconfiguration techniques and design process are described in Section 2. A comparison between different reconfiguration techniques is given in Section 3. Reconfigurable antennas for cognitive radio, MIMO, satellite and biomedical applications are highlighted in Section 4. Finally, Section 5 provides conclusions and future directions.

\section{Classification of Reconfigurable Antennas}

Based on the operational properties dynamically adjusted, e.g. frequency of operation, radiation pattern, polarization or a combination of any of these properties, reconfigurable antennas can be classified as follows:

1. Frequency Reconfigurable Antennas: These antennas can be developed by two mechanisms: electrical or mechanical. The electrical mechanism employs discrete tuning and continuous tuning methods. Discrete tuning can be achieved by radio frequency (RF) switches and continuous tuning can be achieved by varactor diodes. The mechanical mechanism employs the impedance loading tunable materials such as liquid crystals, metasurface to achieve the frequency reconfiguration.

2. Pattern Reconfigurable Antennas: These antennas use movable/rotatable structure like metasurface or including switchable in reactively loaded capacitive elements for the intentional modification of the spherical distribution of radiation pattern.

3. Polarization Reconfigurable Antennas: These antennas use switching between different polarizations, i.e. from linear polarization to left hand circular polarization (LHCP) and right hand circular polarization (RHCP), using multi modes structure or metasurface. To reduce the polarization mismatch, losses in portable devices, switching between horizontal, vertical and circular polarizations are needed.

4. Compound Reconfigurable Antennas: These antennas use simultaneous tuning of several antenna parameters, e.g. frequency and radiation pattern, for independent reconfiguration of operating frequency, radiation pattern and polarization, via a parasitic pixel layer.

\subsection{Reconfiguration Techniques}

Based on the requirement on the reconfiguration property of the antenna, there are four major types of reconfiguration techniques: electrical, optical, mechanical and material [3]-[4].The reconfiguration techniques are presented in Figure 1. 


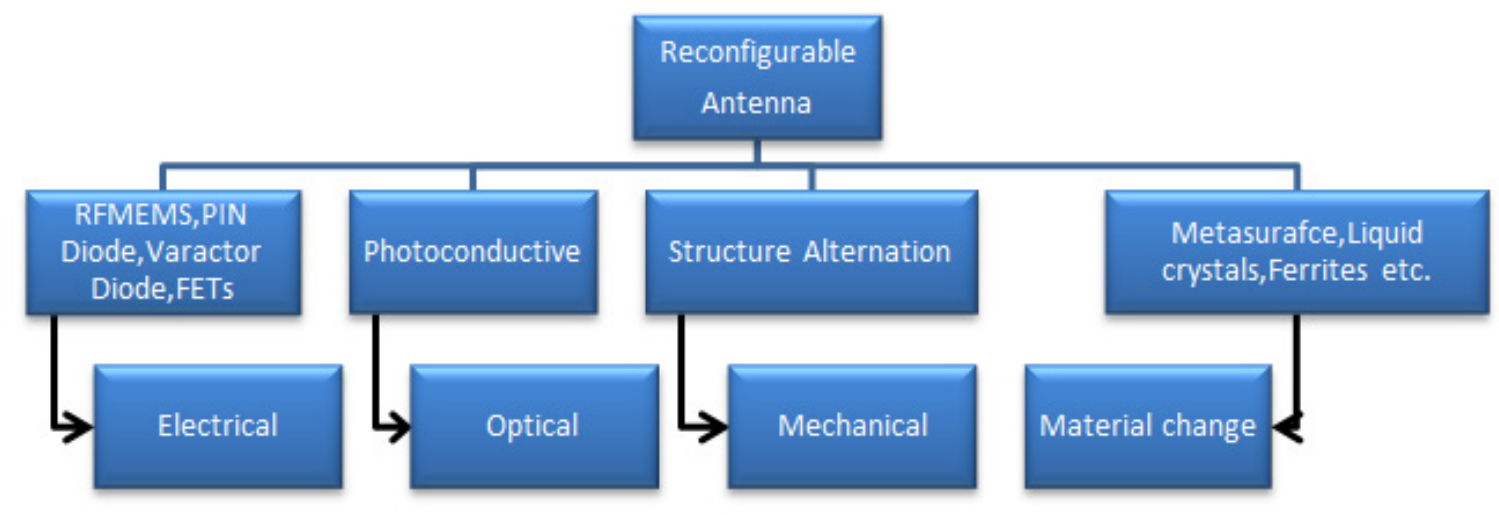

Figure 1. Antenna reconfiguration techniques

Electrical reconfiguration techniques are based on the use of switches to connect or disconnect antenna parts and redistribute the currents by altering the radiated fields of the antenna's effective aperture [5]-[6]. Radio-frequency microelectromechanical systems (RF-MEMS), PIN diodes, varactor diodes, or field effect transistors (FETs) are integrated into the antenna to redirect their source currents. RF-MEMS switches based antennas rely on the mechanical movement of the switches to achieve reconfiguration. Many antenna designs have resorted to RF-MEMS to reconfigure their performance [7]-[14]. The switching speed of RF-MEMS switchs is in the range of 1-200 $\mu \mathrm{sec}$ which is low for some applications [15]. PIN diodes and varactor diodes have faster switching speed as compared to RF-MEMS switches and are in the range of 1-100 nsec [15]. Reconfigurable antennas using PIN diodes have more dynamic reconfiguration ability as compared to RF-MEMS reconfigurable antennas [16]-[26], [97], [99]. Reconfigurable antennas using varactor diodes have tuning ability based on integrating a variable capacitor into the antenna structure. The capacitance of the varactor can be varied by varying the biasing voltage [27]-[35]. Optical reconfiguration techniques rely on photoconductive switching elements [36]-[41]. The optical switches incorporated into an antenna structure become conductive once they are subjected to a laser beam. The integrated laser diodes generate the laser beam. Mechanically reconfigurable antennas can be achieved by altering the structure of the source antenna using actuators [42]-[45]. Finally, reconfigurable antennas can be implemented using smart materials such as metamaterials [93]-[94], [98], ferrites, and liquid crystals [46], dielectric fluids etc.

The corresponding reconfigurability for each of the four-reconfiguration techniques can be obtained either by a change in the antenna surface current distribution, a change in the antenna physical structure, a change in the feeding network, or a change in the antenna radiating edges. The change in one parameter in the antenna characteristics may affect the other parameters. Therefore, RF antenna designers should be careful during the design stage to analyse all the characteristics simultaneously to achieve the required reconfiguration properties.

\subsection{Advantages of Reconfigurable Antennas}

Reconfigurable antennas can support more than one wireless standard, and deliver the same performance as that of multiple antennas. Hence, reconfigurable antennas have the following advantages: (i) low cost, low volume, simple integration, and good isolation between different wireless standards, (ii) low front-end processing that means no need for front-end filtering and good out-of-band rejection, (iii) best candidate for software-defined radios which can adapt to new surroundings, and (iv) change functionality as per the mission changes, act as a single element or as an array, providing narrow band or wideband as per the requirements.

The cost of the reconfigurable antennas can be linked to different parameters as summarized below: (i) design of the biasing network for activation/deactivation of the elements in the antenna structure, (ii) required power consumption of active components, (iii) generation of harmonics and intermodulation products, and (iv) fast tuning of the antenna radiation characteristics to assure a correct functioning of the system.

\subsection{Electrically Reconfigurable Antennas}

Electronic switching components such as RF-MEMS, PIN diodes, varactor diodes or FETs are used in electrically reconfigurable antennas for surface current distributions by altering the antenna radiating structures or radiating edges. The integration of switches into the antenna structure makes it easier for designers to reach the desired reconfigurable functionality [47].

The electrical mechanism employs discrete tuning and continuous tuning methods. These can be achieved by using p-i-n (PIN) diodes, varactor diodes, and field-effect-transistors (FETs). For operating these electronic components in the antenna circuit, direct-current (DC) source and biasing circuits are needed. An electrical reconfigurable antenna thus relies on a DC electrical source and electronic switching components which have an adverse effect on the operation and performance of the antenna. 


\subsection{Optically Reconfigurable Antennas}

Optically reconfigurable antenna comes under the class of radiating elements that has the capability of changing the radiation properties with the use of switches which may be optical activation of silicon switches of reactive elements. The metal wires that may interfere with the antenna's radiation characteristics can be eliminated in case of optically controlled devices. The use of additional metallic microstrip or wired biasing lines makes the antenna complex and interference among the required radiation pattern makes the major issues in case of DC controlled microstrip antennas, can be overcome using optically controlled reconfigurable antenna.

Resonant Frequency of an antenna can also be achieved by optically controlled switches. It is more preferable than electrical switches as optical control has more advantage over electrical control. Even at high microwave frequencies, the optical signal isolates the controlling optical signal from the controlled microwave signal. Optically controlled devices have the switching speed of 0.1-1 MHz. The reconfiguration in the frequency response from single-band to dual- band can be achieved by the use of photoconductive switches.

Frequency agility of the antenna can be implemented by using the optical properties of P3HT (3-hexylthiophene), which is an organic semiconductor polymer that shows semiconductor properties based on organic components. Due to some advantages such as easy fabrication, mechanical flexibility, and tunable optical properties having good spectral overlap with optical wavelength irradiation and high charge-carrier mobility in addition with low band gap, organic semiconductor polymer is more preferred in many applications. Stability and solubility are two important features of organic semiconductor polymer that signifies it is stable in ambient condition and soluble in common organic solvents. The bandgap of P3HT is very small, approximately $1.9 \mathrm{eV}$ and the absorption peak in the visible spectrum ranges from 450 to $600 \mathrm{~nm}$.

P3HT can be used as a patch material in case of an antenna that can be optically controlled. When the light source illuminates the organic polymer, then an electron-hole plasma region is induced as in a semiconductor material the photon energy is greater than the bandgap energy. This results a change in the resonant properties of the antenna.

When laser light is incident on a semiconductor material such as silicon, gallium arsenide, an optical switch is formed and results in excitation of electrons from valence to conduction band for creating a conduction channel. Optically reconfigurable antenna is a type of antenna where we can achieve antenna reconfiguration by integrating a switch into it. In the absence of biasing lines, optical switches compensate the lossy behaviour and uses laser light for their activation [62]-[64]. The main job is related with the switches that can be activated on the antenna structure.

\subsection{Mechanical/Physically Reconfigurable Antennas}

Antennas can also be reconfigured by physically altering the antenna radiating structure. The tuning of the antenna is achieved by a structural modification of the antenna radiating parts [65]. The importance of this technique is that it does not relay on any switch mechanisms, biasing lines or optical fiber/laser diode integration. On the other hand, this technique depends on the limitation of the device to be physically reconfigured.

\subsection{Reconfigurable Antennas Based on Smart Materials}

Antennas are also made reconfigurable through a change in the substrate characteristics by using materials such as liquid crystals, dielectric fluids, ferrites or metasurfaces. The change in the material is achieved by a change in the relative electric permittivity or magnetic permeability. In fact, a liquid crystal is a nonlinear material whose dielectric constant can be changed under different voltage levels, by altering the orientation of the liquid crystal molecules. As for a ferrite material, a static applied electric/magnetic field can change the relative material permittivity/permeability. In metasurfaced antenna, the metasurface is placed directly atop the patch antenna and is rotated. This change the equivalent relative permittivity of the structure by which the resonant frequency of the antenna can be tuned. Frequency tuning can also be achieved using controllable electrical properties materials like barium-strontium-titanate (BST), yttrium iron garnet (YIG), liquid crystals, artificial fluids and dielectric fluids. [66]-[79].

\subsubsection{Frequency Reconfigurable Antenna Using Metasurface}

The frequency reconfigurable metasurfaced antenna consists of a patch antenna (source antenna) and a metasurface (MS). The metasurface consists of rectangular-loop unit cells placed periodically in the vertical and horizontal directions. MS are designed to have circular shape and occupy the same area as that of patch antenna for easy reconfigurable operation of the antenna.

Metamaterials can be extended three-dimensionally by arranging small electrical scatterers or holes in a two-dimensional pattern on a surface [77]. Metamaterials are known as double negative (DNG) materials because their permeability and permittivity are simultaneously negative in a given frequency band. Metamaterials possess a negative index because of their negative permittivity and permeability, and have near zero refractive index. The ability to control and manipulate electromagnetic behaviour differentiates metamaterials from traditional materials [95]. The two-dimensional equivalent of metamaterials is called metasurface (MS). A metasurface has the advantages of taking up a small physical space and being a low-loss structure [77]. With its concise planar 
configuration and low price, a MS can be used to develop planar antennas. Placing a MS on top of a patch antenna can improve the performance of the antenna. The amalgamation of a MS and a patch antenna is called a MS antenna. The geometries of patch antenna, metasurface and unit cell is shown in figure 2 . The non-copper side of the MS is placed in direct contact with the radiator of the patch antenna. The frequency reconfigurability of the antenna can be achieved by rotating the MS around the center relative to the patch antenna. The antenna is microstrip fed using a $50-\Omega$ feed-line. The diameter of the circular ground plane is $20 \mathrm{~mm}$ and the substrate used is a Rogers substrates RO4350B, having thickness of $\varepsilon_{r}=3.48$. The rotation angle $\theta_{R}$ is measured from the y-axis of the unit cell as shown in Figure 2(b). As the rotation angle $\theta_{R}$ increases, the permittivity of the metasurface decreases and shifts up the resonant frequency of the FRMS antenna. Hence, the resonant frequency of the FRMS antenna is proportional to the rotation angle of the metasurface. As the angle of the rotation increases from $10^{\circ}$ to $25^{\circ}, 35^{\circ}, 50^{\circ}, 80^{\circ}$, the resonant frequency increases from 4.77 to $4.9,5.07$, 5.31 and $5.51 \mathrm{GHz}$, respectively as shown in Table 1. The $\mathrm{S}_{11}$ plot of the designed antenna is shown in figure 6 . The simulated s-parameters value of unit cell for 4 to $6 \mathrm{GHz}$ is demonstrated in table 2 , table 3 , table 4 and table 5 . The variation of $\varepsilon_{r}$ and $\mu_{r}$ value of unit cell after rotation is shown in figure 5 (a) and figure $5(\mathrm{~b})$.

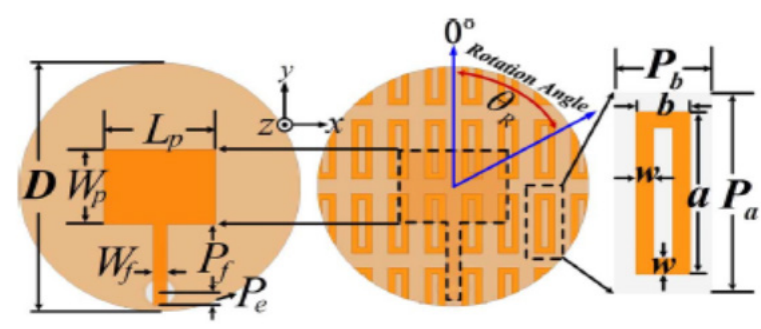

(a)

(b)

(c)

Figure 2. Geometries of (a) Patch Antenna (source antenna), (b) Meatsurface and (c) Unit cell [78].

Table 1. Resonant Frequencies with different rotation angles of MS

\begin{tabular}{|c|c|c|c|c|}
\hline Resonant Frequency $(\mathrm{GHz})$ & 4.77 & 5.07 & 5.27 & 5.51 \\
\hline Rotation Angle of MS & $10^{\circ}$ & $35^{0}$ & $55^{\circ}$ & $80^{\circ}$ \\
\hline
\end{tabular}

The unit cell is designed and simulated by HFSS software as shown in Figure 3.

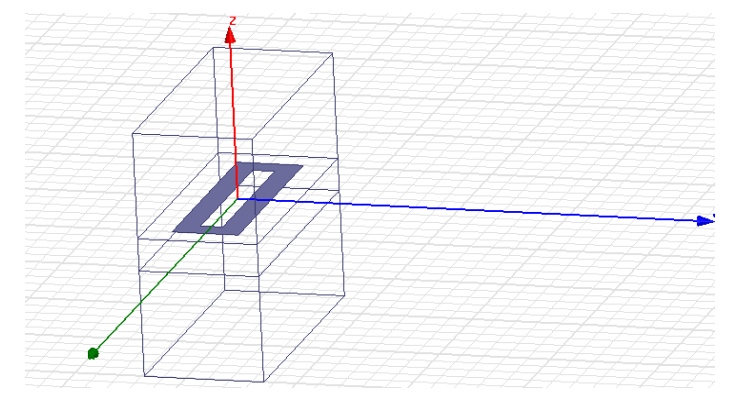

Figure 3. Simulation model of rectangular loop unit cell using HFSS

Table 2. Rectangular loop unit cell $\mathrm{S}_{11}$ magnitude and frequency

\begin{tabular}{|c|c|c|c|c|c|}
\hline $\begin{array}{c}\text { Frequency in } \\
\text { GHz }\end{array}$ & $\begin{array}{l}\text { Mag of S11 } \\
-\mathrm{a}=' 25 \mathrm{deg}^{\prime}\end{array}$ & $\begin{array}{l}\text { Mag of S11 } \\
-\mathrm{a}={ }^{\prime} 45 \mathrm{deg}^{\prime}\end{array}$ & $\begin{array}{l}\text { Mag of S11 } \\
-\mathrm{a}={ }^{\prime} 65 \mathrm{deg}^{\prime}\end{array}$ & $\begin{array}{l}\text { Mag of S11 } \\
-\mathrm{a}={ }^{\prime} 80 \mathrm{deg}^{\prime}\end{array}$ & $\begin{array}{l}\text { Mag of S11 } \\
-\mathrm{a}=\text { ' } 85 \mathrm{deg}^{\prime}\end{array}$ \\
\hline 4.0 & 0.171589471 & 0.21804235 & 0.350296151 & 0.672771673 & 0.875048178 \\
\hline 4.25 & 0.181743449 & 0.230707611 & 0.368935922 & 0.694436358 & 0.886758895 \\
\hline 4.50 & 0.181743449 & 0.243213453 & 0.387084391 & 0.714305081 & 0.89694796 \\
\hline 4.75 & 0.201758632 & 0.255554339 & 0.387084391 & 0.732527861 & 0.905854873 \\
\hline 5.00 & 0.211612251 & 0.267725136 & 0.421888302 & 0.749246331 & 0.913676421 \\
\hline 5.25 & 0.221358421 & 0.279721092 & 0.438539466 & 0.764592754 & 0.920574894 \\
\hline 5.50 & 0.230993703 & 0.291537801 & 0.454690379 & 0.778689589 & 0.926684677 \\
\hline 5.75 & 0.240514754 & 0.303171175 & 0.470343291 & 0.791649461 & 0.932117531 \\
\hline 6.00 & 0.249918299 & 0.314617405 & 0.485501858 & 0.803575413 & 0.936966807 \\
\hline
\end{tabular}


From the rectangular unit cell, we can calculate the $\mathrm{S}_{11}$ and $S_{21}$ parameters by the incident of a plane wave normally on the substrate though the floquent port-1.There is a rotation of E-field with respect to the y-axis of the unit cell, so the reflection coefficient $\left(\mathrm{S}_{11}\right)$ and the transmission coefficient $\left(\mathrm{S}_{21}\right)$ changes with respect to the unit cell rotation. The frequency range used for S-parameters calculation is 4-6 GHz. By providing appropriate master-slave boundary conditions in HFSS software to the unit cell, we analyze the s-parameters. The $S_{11}$ plot and $S_{21}$ plot of unit cell after rotation is shown in figure 4 .

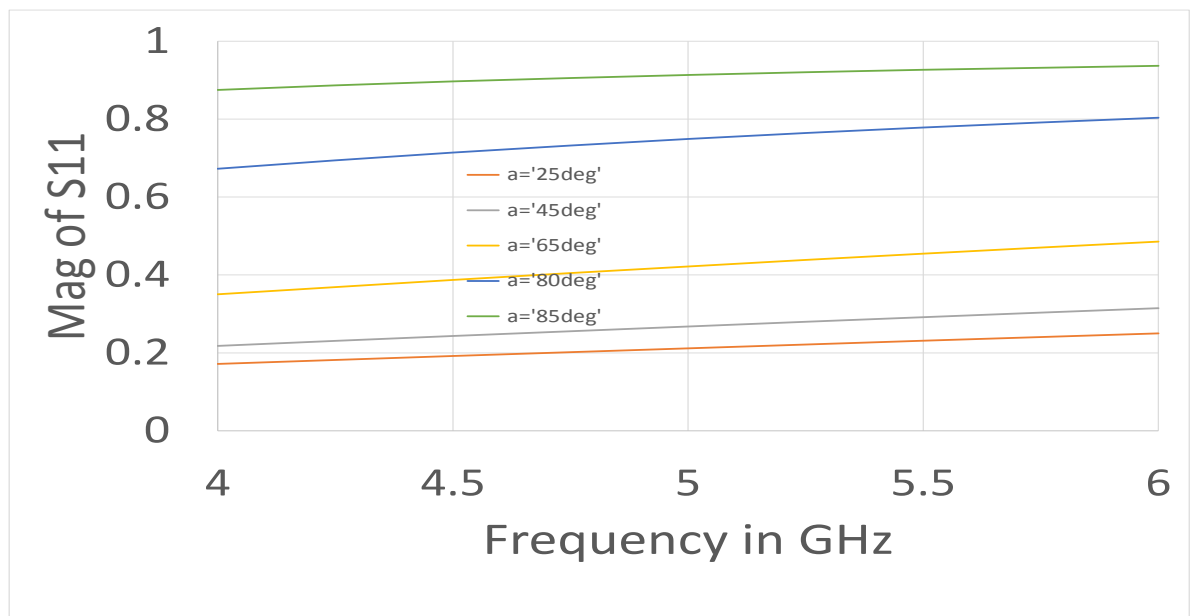

Figure 4 (a). Simulated $\mathrm{S}_{11}$ magnitude w.r.t frequency for different $\mathrm{a}=25^{\circ}, 45^{\circ}, 65^{\circ}, 80^{\circ}$, and $85^{\circ}$ rotation of rectangular loop unit cell

Table 3. Rectangular loop unit cell $\mathrm{S}_{11}$ Phase in radian and frequency in $\mathrm{GHz}$

\begin{tabular}{|c|c|c|c|c|c|}
\hline Frequency in GHz & $\begin{array}{c}\text { Phase of S11 for } \\
\mathrm{a}=25 \mathrm{deg}\end{array}$ & $\begin{array}{c}\text { Phase of S11 for } \\
\mathrm{a}=45 \mathrm{deg}\end{array}$ & $\begin{array}{c}\text { Phase of S11 for } \\
\mathrm{a}=65 \mathrm{deg}\end{array}$ & $\begin{array}{c}\text { Phase of S11 for } \\
\mathrm{a}=80 \mathrm{deg}\end{array}$ & $\begin{array}{c}\text { Phase of S11 for } \\
\mathrm{a}=85 \mathrm{deg}\end{array}$ \\
\hline 4.00 & -2.621685293 & -2.476501772 & -2.339610547 & -2.479044783 & -2.723036987 \\
\hline 4.25 & -2.686797391 & -2.532246894 & -2.385131489 & -2.51922573 & -2.753051513 \\
\hline 4.50 & -2.751841732 & -2.587875894 & -2.43028512 & -2.557714847 & -2.780848429 \\
\hline 4.75 & -2.816814862 & -2.643383857 & -2.475063162 & -2.594608543 & -2.806690016 \\
\hline 5.00 & -2.881713712 & -2.698766374 & -2.519459212 & -2.630001929 & -2.830802172 \\
\hline 5.25 & -2.946535534 & -2.754019456 & -2.563468595 & -2.663987529 & -2.853379812 \\
\hline 5.50 & -3.011277834 & -2.809139468 & -2.60708822 & -2.696654367 & -2.874591512 \\
\hline 5.75 & -3.075938316 & -2.864123052 & -2.650316442 & -2.728087366 & -2.89458346 \\
\hline 6.00 & -3.140514833 & -2.918967063 & -2.693152928 & -2.758366996 & -2.913482793 \\
\hline
\end{tabular}

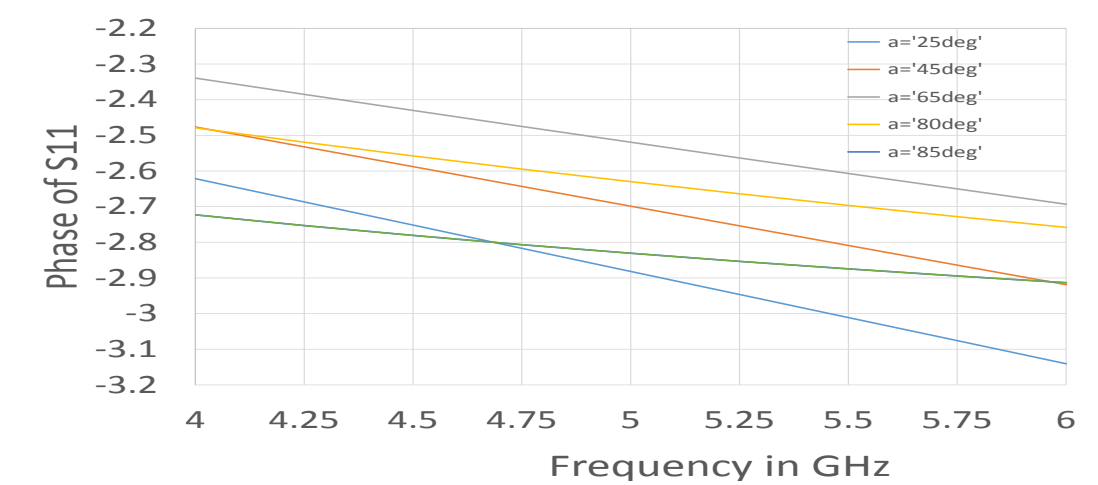

Figure 4 (b). Simulated $S_{11}$ phase in radian w.r.t frequency for different $\mathrm{a}=25^{\circ}, 45^{\circ}, 65^{\circ}, 80^{\circ}$, and $85^{\circ}$ rotation of rectangular loop unit cell 
Table 4. Rectangular loop unit cell $\mathrm{S}_{21}$ magnitude and frequency

\begin{tabular}{|c|c|c|c|c|c|}
\hline $\begin{array}{c}\text { Frequency in } \\
\mathrm{GHz}\end{array}$ & $\begin{array}{c}\text { Mag of S21-for } \\
a=' 25 \mathrm{deg}\end{array}$ & $\begin{array}{c}\text { Mag of S21 -for } \\
a==^{\prime} 45 \mathrm{deg}^{\prime}\end{array}$ & $\begin{array}{c}\text { Mag of S21-for } \\
\mathrm{a}^{\prime} \text { ' } 65 \mathrm{deg}^{\prime}\end{array}$ & $\begin{array}{c}\text { Mag of S21 -for } \\
a^{=}=80 \mathrm{deg}^{\prime}\end{array}$ & $\begin{array}{c}\text { Mag of S21 -for } \\
a={ }^{\prime} 85 \mathrm{deg}^{\prime}\end{array}$ \\
\hline 4.0 & 0.984742414 & 0.975398351 & 0.935770814 & 0.738184466 & 0.481871842 \\
\hline 4.25 & 0.982895549 & 0.9724521 & 0.928542368 & 0.717837726 & 0.460043277 \\
\hline 4.50 & 0.980959161 & 0.969371783 & 0.921088658 & 0.69807231 & 0.439926375 \\
\hline 4.75 & 0.978936642 & 0.966164046 & 0.913435949 & 0.678933587 & 0.421361099 \\
\hline 5.00 & 0.976831446 & 0.962835599 & 0.905609823 & 0.660450576 & 0.404200795 \\
\hline 5.25 & 0.974647073 & 0.959393182 & 0.897635018 & 0.642639035 & 0.388312417 \\
\hline 5.50 & 0.972387054 & 0.955843518 & 0.889535307 & 0.625504143 & 0.373576038 \\
\hline 5.75 & 0.970054945 & 0.952193281 & 0.881333389 & 0.609042777 & 0.359884002 \\
\hline 6.00 & 0.967654312 & 0.948449056 & 0.873050814 & 0.593245427 & 0.347139895 \\
\hline
\end{tabular}

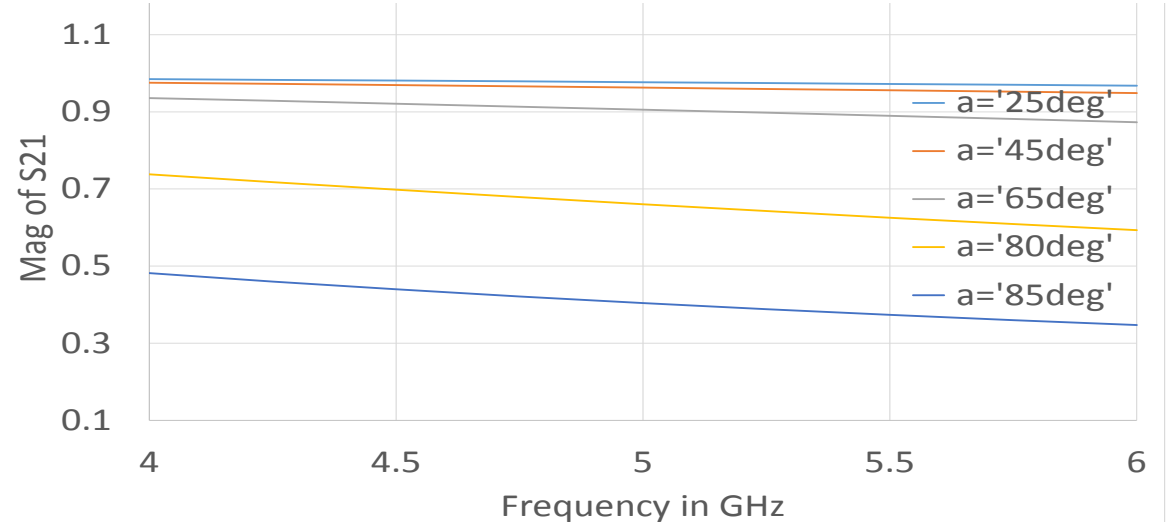

Figure 4 (c). Simulated $\mathrm{S}_{21}$ magnitude w.r.t frequency for different $\mathrm{a}=25^{\circ}, 45^{\circ}, 65^{\circ}, 80^{\circ}$, and $85^{\circ}$ rotation of rectangular loop unit cell

Table 5. Rectangular loop unit cell $\mathrm{S}_{21}$ Phase in radian and frequency in $\mathrm{GHz}$

\begin{tabular}{|c|c|c|c|c|c|}
\hline $\begin{array}{c}\text { Frequency in } \\
\mathrm{GHz}\end{array}$ & $\begin{array}{c}\text { Phase of S11 for } \\
\mathrm{a}=25 \mathrm{deg}\end{array}$ & $\begin{array}{c}\text { Phase of S11 for } \\
\mathrm{a}=45 \mathrm{deg}\end{array}$ & $\begin{array}{c}\text { Phase of S11 for } \\
\mathrm{a}=65 \mathrm{deg}\end{array}$ & $\begin{array}{c}\text { Phase of S11 for } \\
\mathrm{a}=80 \mathrm{deg}\end{array}$ & $\begin{array}{c}\text { Phase of S11 for } \\
\mathrm{a}=85 \mathrm{deg}\end{array}$ \\
\hline 4.00 & -1.048412196 & -0.903231913 & -0.766341669 & -0.90577349 & -1.149764406 \\
\hline 4.25 & -1.113529565 & -0.958982355 & -0.811868325 & -0.945959198 & -1.179783428 \\
\hline 4.50 & -1.178578213 & -1.014615903 & -0.857026728 & -0.98445318 & -1.207585178 \\
\hline 4.75 & -1.243555389 & -1.070128246 & -0.901809351 & -1.021351882 & -1.233431817 \\
\hline 5.00 & -1.308458442 & -1.125515315 & -0.94621021 & -1.056750433 & -1.257549169 \\
\hline 5.25 & -1.373284798 & -1.180773257 & -0.990224789 & -1.09074136 & -1.280132116 \\
\hline 5.50 & -1.438031935 & -1.235898402 & -1.033849956 & -1.123413685 & -1.301349236 \\
\hline 5.75 & -1.50269735 & -1.290887234 & -1.077083879 & -1.154852324 & -1.321346753 \\
\hline 6.00 & -1.567278533 & -1.345736356 & -1.119925927 & -1.18513774 & -1.340251868 \\
\hline
\end{tabular}




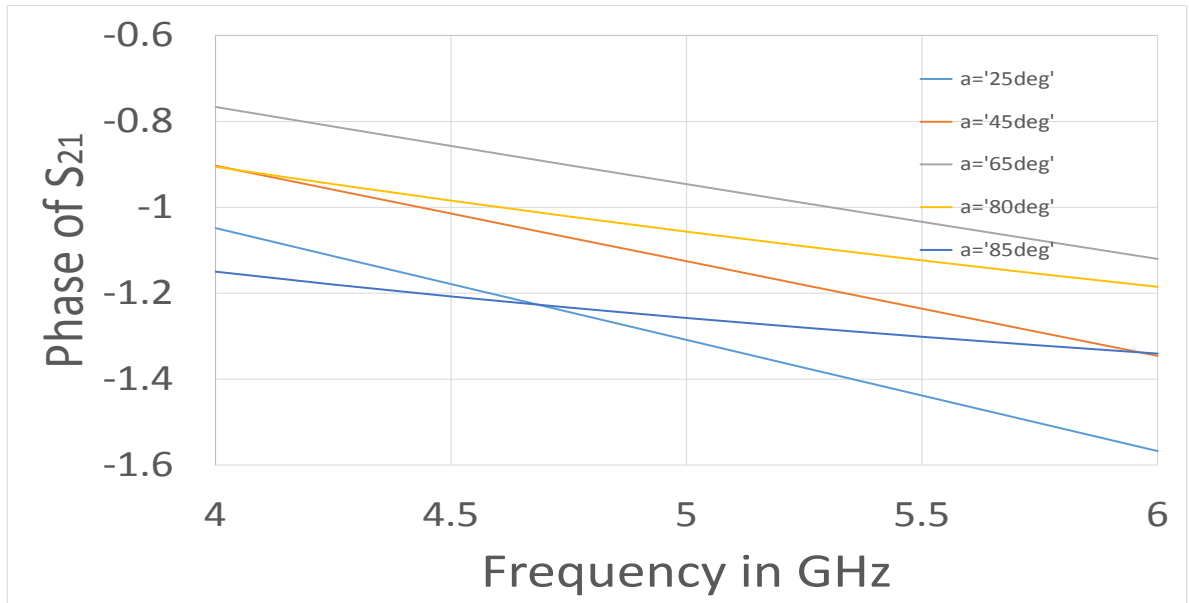

Figure 4 (d). Simulated $\mathrm{S}_{21}$ Phase in Radian w.r.t frequency for different $\mathrm{a}=25^{\circ}, 45^{\circ}, 65^{\circ}, 80^{\circ}$, and $85^{\circ}$ rotation of rectangular loop unit cell

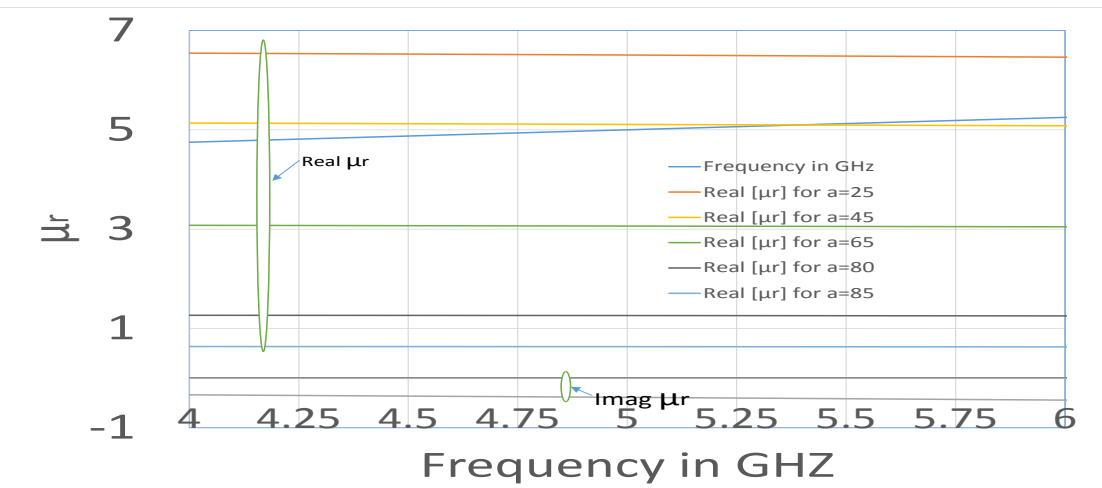

Figure 5 (a). Calculated $\mu_{r} \mu$ r w.r.t frequency for different $\mathrm{a}=25^{\circ}, 45^{\circ}, 65^{\circ}, 80^{\circ}$, and $85^{\circ}$ rotation of rectangular loop unit cell

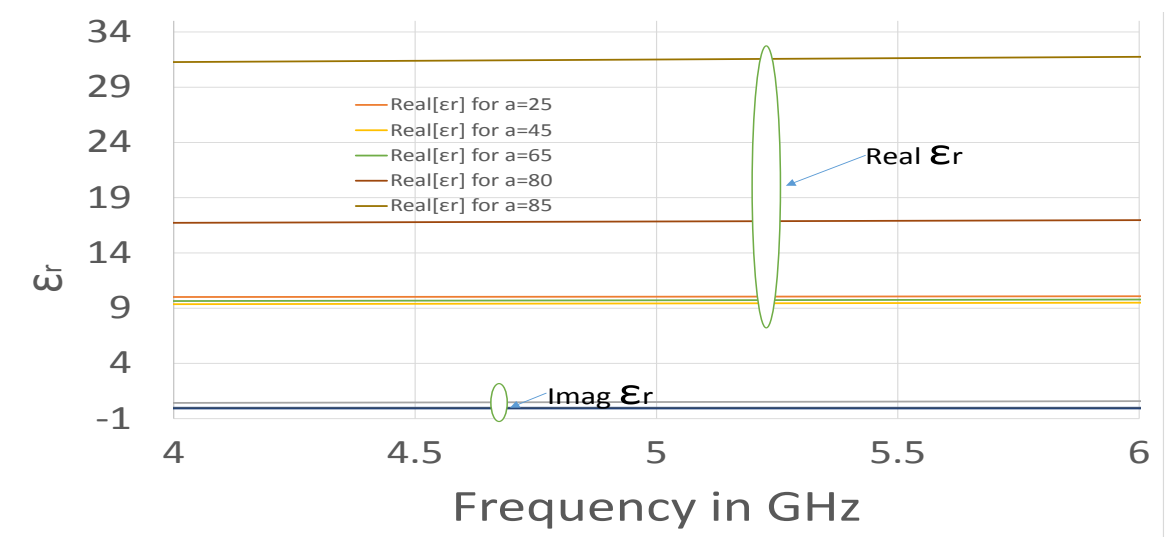

Figure 5 (b). Calculated $\mathcal{E}_{\mathrm{r}}$ w.r.t frequency for different a $=25^{\circ}, 45^{\circ}, 65^{\circ}, 80^{\circ}$, and $85^{\circ}$ rotation of rectangular loop unit cell 


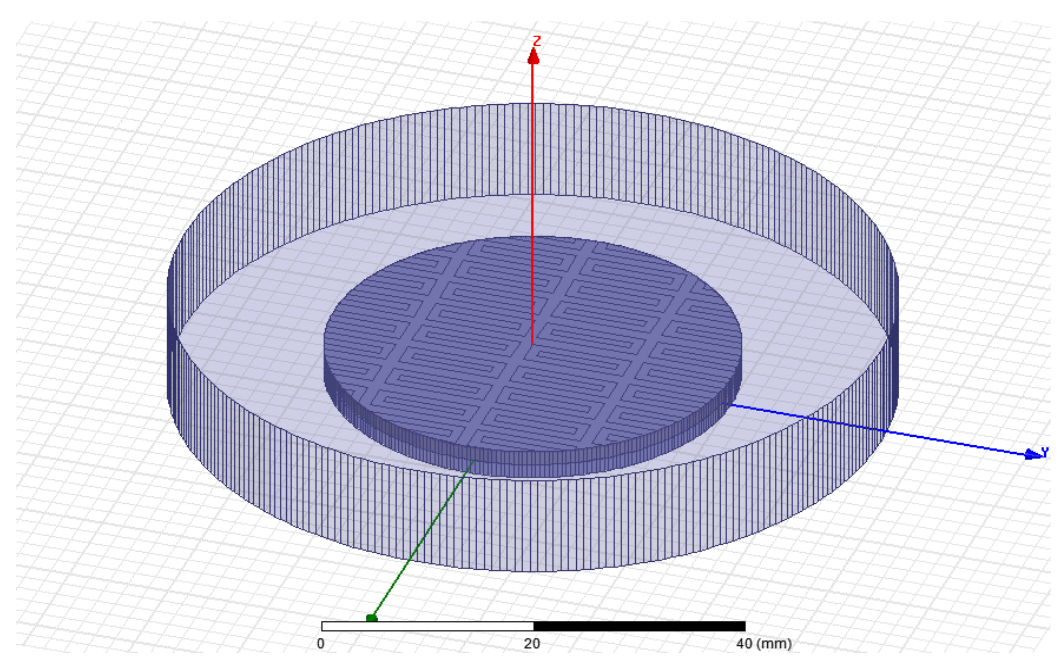

Figure 5. FRMS antenna using HFSS

Frequency Reconfigurability:

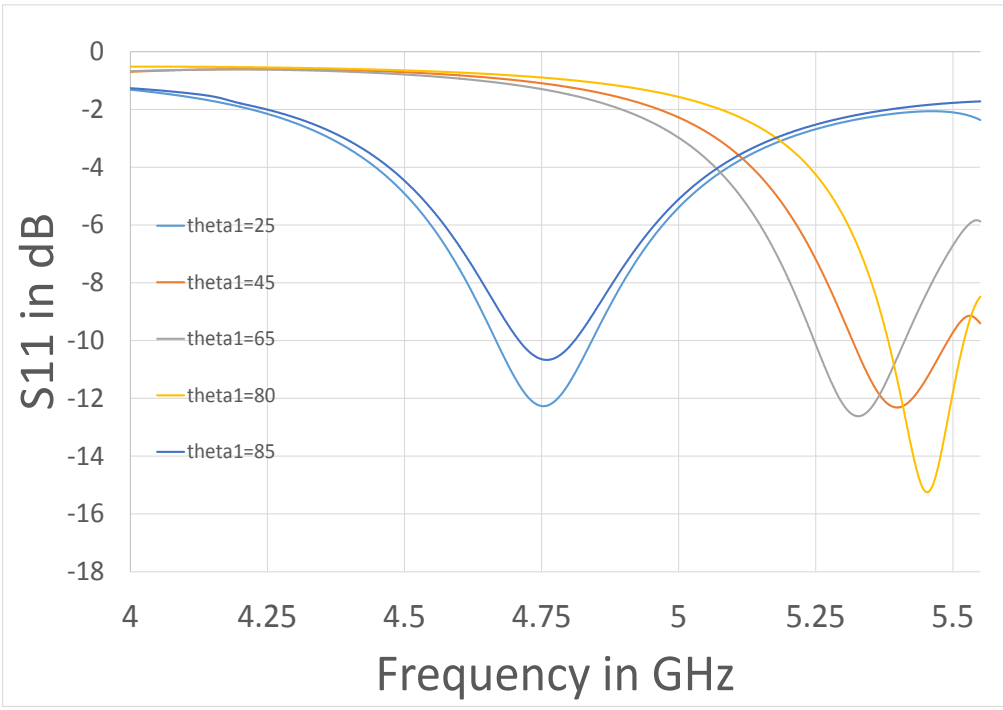

Figure 6. Simulated $\mathrm{S}_{11}$ of FRMS antenna with different rotation angles

\subsubsection{Polarization Reconfigurable Antenna Using} Metasurface

In polarization reconfigurable antenna, the direction of electric field on the wave front is changed during reconfiguration. Polarization reconfigurable antennas can usually be switched from circular polarization to right-hand circular polarization [80].

The polarization reconfigurable metasurfaced antenna (PRMS) consists of a planar metasurface (MS) placed directly atop of a planar slot antenna. Both the planar slot antenna and metasurface are having circular shape with a diameter of $78 \mathrm{~mm}\left(0.9 \lambda_{0}\right)$ to make compact and low profile PRMS antenna. The metasurface (MS) is composed of corner truncated square unit cells. The polarization reconfigurable metasurfaced antenna (PRMS) antenna can be reconfigured to linear polarization, left-hand and right-hand by rotating the metasurface (MS) around the center with respect to the slot antenna. The dimensions of PRMS antenna design are listed in Table 7. The slot antenna is designed on a double-sided substrate as shown in Figure 7 (a) and the metasurface is designed on a single sided substrate as shown in Figure 7(b). The Rogers substrate RO4350B, having dielectric constant $\mathcal{E}_{r}=3.48$ and a thickness of $1.524 \mathrm{~mm}$ is used to design the antenna in HFSS. In assembling of the PRMS antenna, the non-copper side of the metasurface (MS) is placed atop of the slot antenna and is in direct contact with the feed. The rotation angle $\theta_{R}$ is measured from the y-axis of the unit cell as shown in the Figure 7(a). The PRMS antenna is left hand circular polarization (LHCP) at $\theta_{R}=0^{0}$ and right hand circular polarization (RHCP) at $\theta_{R}=90^{\circ}$. The metasurface (MS) is a mirror image of itself at $\theta_{R}=0^{0}$ and $\theta_{R}$ 
$=90^{\circ}$. Hence the performance of the antenna is identical in LHCP and RHCP. The PRMS antenna is linear polarization along the $y$-axis same as the source slot antenna when $\theta_{R}=45^{\circ}$ and $\theta_{R}=135^{\circ}$.In this way, the polarization of the antenna can be reconfigured to LHCP, RHLP and LP by rotating the metasurface mechanically around the center with respect to source slot antenna. The polarization of the antenna at $\theta_{R}=0^{0}, 45^{\circ}, 90^{\circ}$ and $135^{\circ}$ is shown in Figure 8.

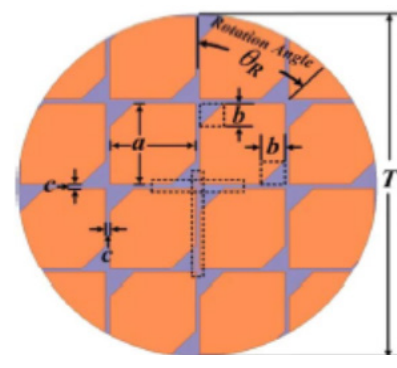

(a)

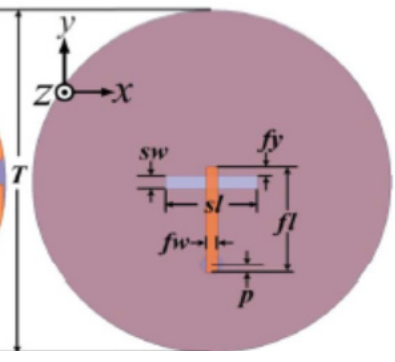

b
Figure 7. (a) Geometries of eetasurface (MS) and (b) Slot ntenna [79]

Table 7. Dimensions of PRMS Antenna (Unit in mm)

\begin{tabular}{|c|c|c|c|c|c|c|c|c|c|}
\hline $\mathrm{A}$ & $\mathrm{b}$ & $\mathrm{c}$ & $S w$ & $s l$ & $f w$ & $f l$ & $f y$ & $P$ & $T$ \\
\hline 18.5 & 5.3 & 1 & 3 & 20 & 2.5 & 24.5 & 2 & 2 & 78 \\
\hline
\end{tabular}

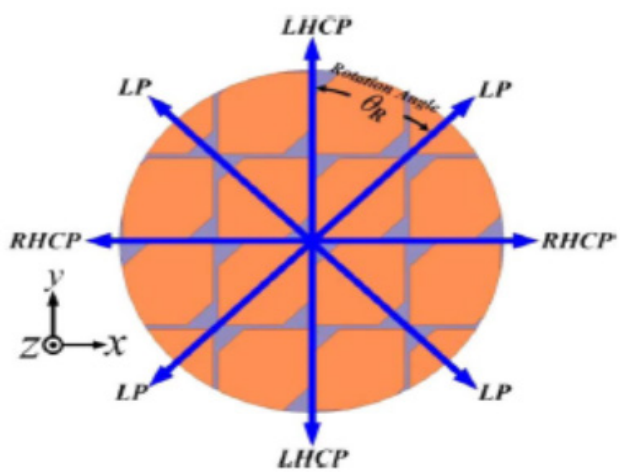

Figure 8. Antenna Polarization at different rotation angles $\theta_{R}$ [79]

\subsubsection{Pattern Reconfigurable Antenna Using Metasurface}

The Pattern reconfigurable metasurfaced (PaRMS) antenna is composed of a planar semi-circular metasurface (MS) placed directly atop of a planar circular patch antenna with diameter $70 \mathrm{~mm}\left(1.2 \lambda_{0}\right)$, making it compact and low profile. The Main beam direction of the antenna has an angle of $32^{0}$ from the boresight direction. By rotating the Metasurface (MS) around the centre of the patch antenna, the antenna beam can be steered continuously. The antenna has an operating bandwidth from 5.4 to $5.6 \mathrm{GHz}$ and measured peak realised gain of $7.2 \mathrm{dBi}$. The geometry of the PARMS antenna is circular shape with diameter $\mathrm{D}_{\mathrm{a}}$. It consists of a patch antenna and a metasurface (MS) as shown in the Figure 9. The metasurface has a semi-circular shape consisting of square patches unit cells with size $a \times a$ $\mathrm{mm}^{2}$. The gap between the unit cells is ' $\mathrm{g}$ ' $\mathrm{mm}$. The diameter of the circular radiator of patch antenna is $D_{p}$. The radiator is printed on one side of the substrate and the ground plane is on the other side. The patch antenna is fed at the center of the patch through a subminiature version A (SMA) connector as shown in Figure 10. The dimensions of the PaRMS antenna design are listed in Table 8.

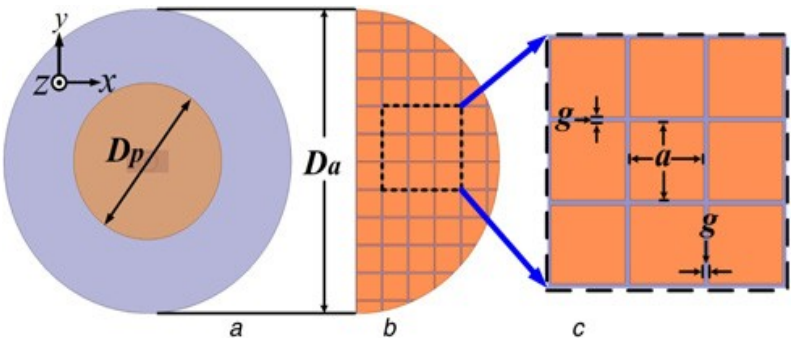

Figure 9. (a) Patch antenna (b) Metasurface (MS) (c) Unit cell [80].

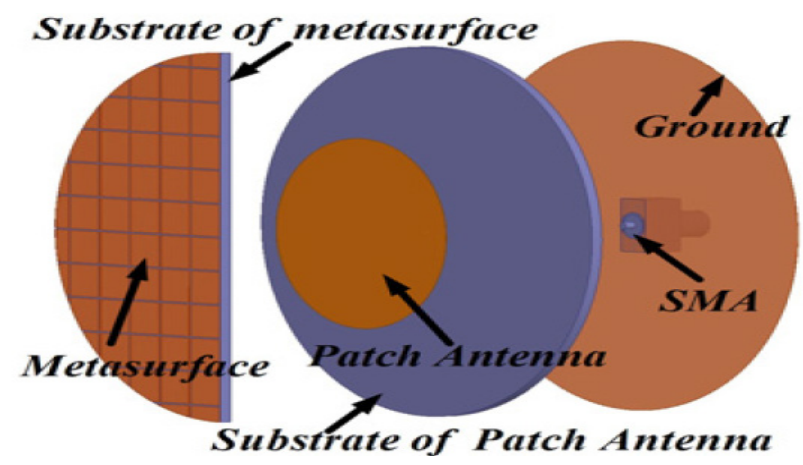

Figure 10. Assembly Schematic of PaRMS Antenna [80]

Table 8. Dimensions of PaRMS Antenna in $\mathrm{mm}$

\begin{tabular}{|c|c|c|c|}
\hline $\mathrm{a}$ & $\mathrm{G}$ & $\mathrm{D}_{\mathrm{p}}$ & $\mathrm{D}_{\mathrm{a}}$ \\
\hline 5.9 & 0.35 & 36 & 70 \\
\hline
\end{tabular}

The Substrates used for the designing of PaRMS antenna is Rogers substrates RO4350B, having a dielectric constant $\epsilon_{\mathrm{r}}=3.48$ and a thickness of 1.524. The no-copper side of the metasurface is placed atop of the patch antenna as shown in Figure 6. The Pattern reconfiguration can be achieved by rotating the semi-circular metasurface with respect to the centre of the patch antenna.

The circular patch diameter $\mathrm{Dp}$ and the unit cell dimension a, have the significant effects on the antenna performance, with a mainly affecting S11 and Dp affecting both $\mathrm{S} 11$ and beam direction. There are two resonances of $\mathrm{S} 11$ at around $4.8 \mathrm{GHz}$ and $5.7 \mathrm{GHz}$ with $\mathrm{a}=7 \mathrm{~mm}$. These two resonances move closer to each other as ' $a$ ' decreases and merge together at $5.12 \mathrm{GHz}$ with $\mathrm{a}=5 \mathrm{~mm}$. In the radiation pattern, the main beam is around $-32^{\circ}$ and does not change with different values of ' $a$ '. When the ' $D_{p}$ ' value increases from 36 to $42 \mathrm{~mm}$ and $44 \mathrm{~mm}$, the tilt angle of the main beam changes to $-32^{0},-20^{0}$, and $-6^{0}$ respectively. The radiation pattern results of PaRMS antenna are listed in Table 9. 
Table 9. Result of Radiation Patterns

\begin{tabular}{|c|c|c|c|c|c|c|}
\hline Resonant Frequency & \multicolumn{2}{|c|}{$5.4 \mathrm{GHz}$} & \multicolumn{2}{c|}{$5.5 \mathrm{GHz}$} & \multicolumn{2}{c|}{$5.6 \mathrm{GHz}$} \\
\hline Results Type & Simulated & Measured & Simulated & Measured & Simulated & Measured \\
\hline Beam direction, deg & -32 & -32 & -32 & -32 & -30 & -30 \\
\hline HPBW,deg & -6 to -60 & -10 to -58 & -8 to -58 & -8 to -60 & -4 t0 -60 & -4 to -58 \\
\hline Realised peak gain,dBi & 6.8 & 6.2 & 7.7 & 7.1 & 7.8 & 6.5 \\
\hline
\end{tabular}

Table 10. Electrical Properties Comparison of Electrically and Optically Switching

\begin{tabular}{|c|c|c|c|c|}
\hline Electrical Property & RF MEMS & PIN Diode & FETs & Optical Switch \\
\hline Voltage[V] & $20-100$ & $3-5$ & $1.8-3.3$ & $1.8-1.9$ \\
\hline Current[mA] & 0 & $3-20$ & 0.005 & $0-87$ \\
\hline Power Consumption[mW] & $0.05-0.1$ & $5-100$ & $<0.033$ & $0-50$ \\
\hline Switching Speed & $1-200 \mu \mathrm{Sec}$ & $1-100 \mu \mathrm{Sec}$ & $0.02 \mu \mathrm{sec}$ & $3-9 \mu \mathrm{Sec}$ \\
\hline Isolation[1-10GHz] & Very High & High & $22-25 \mathrm{~dB}$ & High \\
\hline Loss(1-10GHz) [10dB] & $0.05-0.2$ & $0.3-1.2$ & $0.7-0.9$ & $0.5-1.5$ \\
\hline
\end{tabular}

\section{Comparison between Different Reconfiguration Techniques}

With the advent of RF-MEMS since 1998, electronic switching components have been widely used to reconfigure antennas [7]. Although RF-MEMS represent an innovative switching mechanism, their response is slower in comparison to PIN diodes and varactors, which have response in order of nanoseconds [81]-[82]. In addition, one of the major advantages of electronic switching components is their good isolation and low-loss property. Therefore, all these types of switches and especially varactors contribute to scalability of reconfigurable antennas.

The integration of electrical switches into the antenna structure is very simple, which can be matched by their nonlinearity effects (capacitive and resistive) and their need for high voltage of RF-MEMS and varactor diodes [83]. Biasing lines are required for the activation of such electrical switches may negatively affect the antenna radiation pattern and add to more losses. The complexity of the antenna structure increases as the number of switches increases due to the additional bypass capacitors and inductors. Hence, the power consumption of the whole system increases which is the disadvantage of electrical reconfiguration technique.

Optical switches provide reliable reconfiguration mechanism especially in comparison to RF-MEMS. The activation or deactivation of the photoconductive switch depends on the incident light from the laser diode and that does not produce harmonics and intermodulation distortion due to their linear behaviour. The optical switches are integrated into the antenna structure without any complicated biasing lines which eliminates unwanted interference, losses and radiation pattern distortion. But the main disadvantages of such switches that they exhibit lossy behaviour and require a complex activation mechanism.
The comparison characteristics for the different switching techniques used on electrically (RFMEMS/PIN/FETs) and optically reconfigurable antennas are listed in Table 10.

In SMV varactor diodes, the capacitance will change from $2.22 \mathrm{pF}$ to $0.3 \mathrm{pF}$ when the reverse bias voltage increases from $0 \mathrm{~V}$ to $20 \mathrm{~V}$. The specific varactor diode is chosen for the required capacitance tuning range due to its low series resistance [55]. The power dissipation of varactor diode is $250 \mathrm{~mW}$ and it has capacitance high ratio at low reverse voltage. But as the large number of varactors used in the antenna design, it makes the design complicated and expensive.

The use of GaAs FETs switches provides less adverse biasing effect on antenna performance. The control voltage of these switches is around $3.3 \mathrm{~V}$ and the dc current consumption is very low, nearly $5 \mu \mathrm{A}$ [84]. This leads to low total power consumption and simple integration of the antenna in portable communication systems. But the insertion loss is high at high frequency and sensitive to RF power overstress, temperature. The 'ON' resistance of a FET is higher than PIN diode which results inferior insertion loss performance of FET switches compared to PIN diode switches.

Physical/mechanical reconfiguration techniques do not require any bias line or resort to laser diodes or optical fibres to achieve reconfigurability. Slow response, cost, size, power source requirements and the complex integration of reconfiguring element into the antenna structure are the disadvantages of mechanical reconfiguration technique.

Ferrite-based reconfigurable antennas are of small size due to ferrite's high relative permittivity and permeability properties. The main disadvantage of ferrite-based reconfigurable antennas is its low efficiency that is a common inconvenience for liquid-crystal-based antennas as well, especially at microwave frequencies [46].

The main advantages of metamaterial antennas are 
compact size, conformal, low cost, high gain, high efficiency, good radiation pattern, low specific absorption rate, constant size and shape when being tuned. No electrical switches and biasing lines are required to achieve the reconfigurability in metasurfaced antenna.

The best reconfiguration technique is always the one that is more satisfying to the constraints of the applications, for example RF-MEMS switches or physical changes in the structure may be more desirable, since they will not include radiation hardened electronics. For terrestrial wireless communications, all options are used depending on the required speed of operation and the overall system requirements. Low frequency metamaterial reconfigurable antennas are used in Bio-medical applications.

\section{Applications}

The advancements in wireless communication applications require new generation of reconfigurable antennas which can adjust to the environments and adopt reconfigurable capabilities as per the surrounding conditions. The reconfigurable antennas are used in cognitive radio system, MIMO systems, satellite communication, biomedical application, military and industrial applications. Some of the applications are presented here.

\subsection{Frequency Reconfigurable Antenna for a Cognitive Radio System}

Due to the rapid growth in the communication system the demand of frequency band increase that leads to scarcity in the RF spectrum. Mainly, the scarcity of RF spectrum arises due to the inefficient spectrum allocation. As the frequency bands are used more, the cognitive radio (CR) comes into account. To overcome the future communication problems cognitive radios are used which improves the spectrum usage efficiently. CR has the capability to use the unoccupied space in a wide frequency range by sensing and detecting the available channels before initializing communication. The development of the CR puts a great challenge to antenna design. In general, the introduction of $\mathrm{CR}$ and allocation of spectrum offers new challenges to the frequency reconfigurable antenna as the antenna can tune the frequency without sacrificing the gain and radiation properties. There is one way to overcome this solution that integration of reconfigurable filter to the antenna structure which is known as filtenna which can be integrated at the feeding line or also on the ground plane of the antenna. Most of the reconfiguration mechanisms are integrated into the ultra-wide band (UWB) antenna in order to operate in multiband. It can be done by using some switches such as ideal switches, optical switches, p-i-n diodes, varactor diodes, linear actuators and also stepper motors are used for rotation of patches. The $p-i-n$ diode switches acts as resistances to the flow of current and requires large amount of DC power for its operation to achieve low insertion loss and it uses complex biasing network. Photodetector switches like laser diodes do not require any biasing line to increase its performance, with some limitations and is operated in fixed bands.

The cognitive radio applications can be achieved by a compact filtennas with large tunable frequency bands [85]. In [85], a planar ultra-wide band monopole antenna with a tunable T-shaped and $\mathrm{H}$-shaped band pass filter helps to achieve tenability where the T-shaped filter is composed of a microstrip resonator with a stub and the $\mathrm{H}$-shaped filter consists of two microstrip resonators connected with each other. The common tuning technique used for both the filters are stub and also a varactor to get miniaturization. As varactor signifies variable capacitance, this implies that with increase in variable capacitance, there is a decrease in the even resonant mode of the resonator without affecting the dominant odd mode. The operating band for T-shaped and H-shaped filtennas are 1.68 and $1.73 \mathrm{GHz}$. Cognitive Radio covers $32.9 \%$ of the frequency tuning range from 4.26 to $5.94 \mathrm{GHz}$ and $36.7 \%$ frequency tuning that ranges from 3.85 to $5.58 \mathrm{GHz}$.

A cognitive radio can monitor the channel and idle frequencies of the channel can be determined. Basically, idle frequency deals with the white space or unused space. The idle frequency is very useful in reconfigurable antenna. After identification of the unused space the reconfigurable antenna have the ability to tune its operation according to the requirement and thus increase the efficiency. Basically, the operation of cognitive radio can be represented in a cycle. The cognitive cycle is shown in Figure 11. The first step involves sensing the antenna and observing the antenna activity. Then the cognitive radio determines the suitable part for communication. After that the communicating antenna achieves the required mode of operation. The last and final step involves the process achieving cognition. This can be done by learning from the previous channel activity. The advantage of the cognitive radio is that it allows the device to self-decide and self-configure. The cognitive radio can self-realize the selected mode of communication [86].

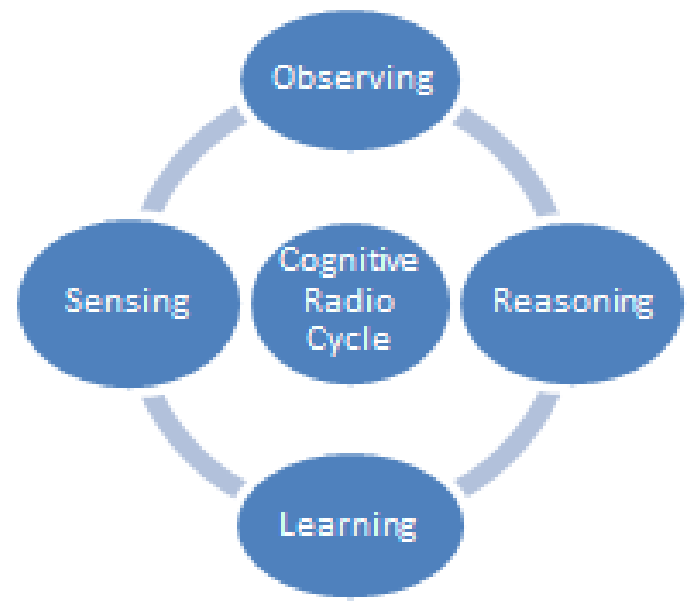

Figure 11. The cognitive radio cycle 


\subsection{Pattern Reconfigurable Antennas for MIMO Systems}

Reconfigurable antennas are used to improve the performance of multi-input multi-output (MIMO) wireless communication system. A MIMO system employs multiple antennas at both the transmitter and the receiver front ends to send different information simultaneously, thereby increasing the communication spectral efficiency in a multipath environment. A MIMO system can adjust the modulation level, coding rate, and the transmission signalling schemes according to the varying channel conditions and user's need. The use of radiation pattern/polarization reconfigurable antennas in a MIMO environment improves the channel reliability, capacity and figure of merit of system performance. Reconfigurable antenna arrays are also an attractive solution for MIMO systems to maintain good communication links, especially for handled devices where space is an important constraint [47].

As an example, we present a design and evaluation of pattern reconfigurable antennas for MIMO applications. Using two electrically steerable passive array radiator (ESPAR) antennas, the effect of uniform beam steering on MIMO system performance is evaluated. The MIMO-ESPAR system reduces the bit error rate (BER) in certain pattern combinations and improves the channel capacity [87]. This ESPAR antenna design consists of one driven monopole in the centre, surrounded by a ring of six uniformly spaced parasitic monopoles. A pair of ESPAR antennas is fabricated on one substrate. The ESPAR patterns and beam angles with respect to test environment is shown in Figure 12 [87].

MIMO based antenna has several advantages such as it ensures a reliable communication between end users and increases the efficiency of spectrum.

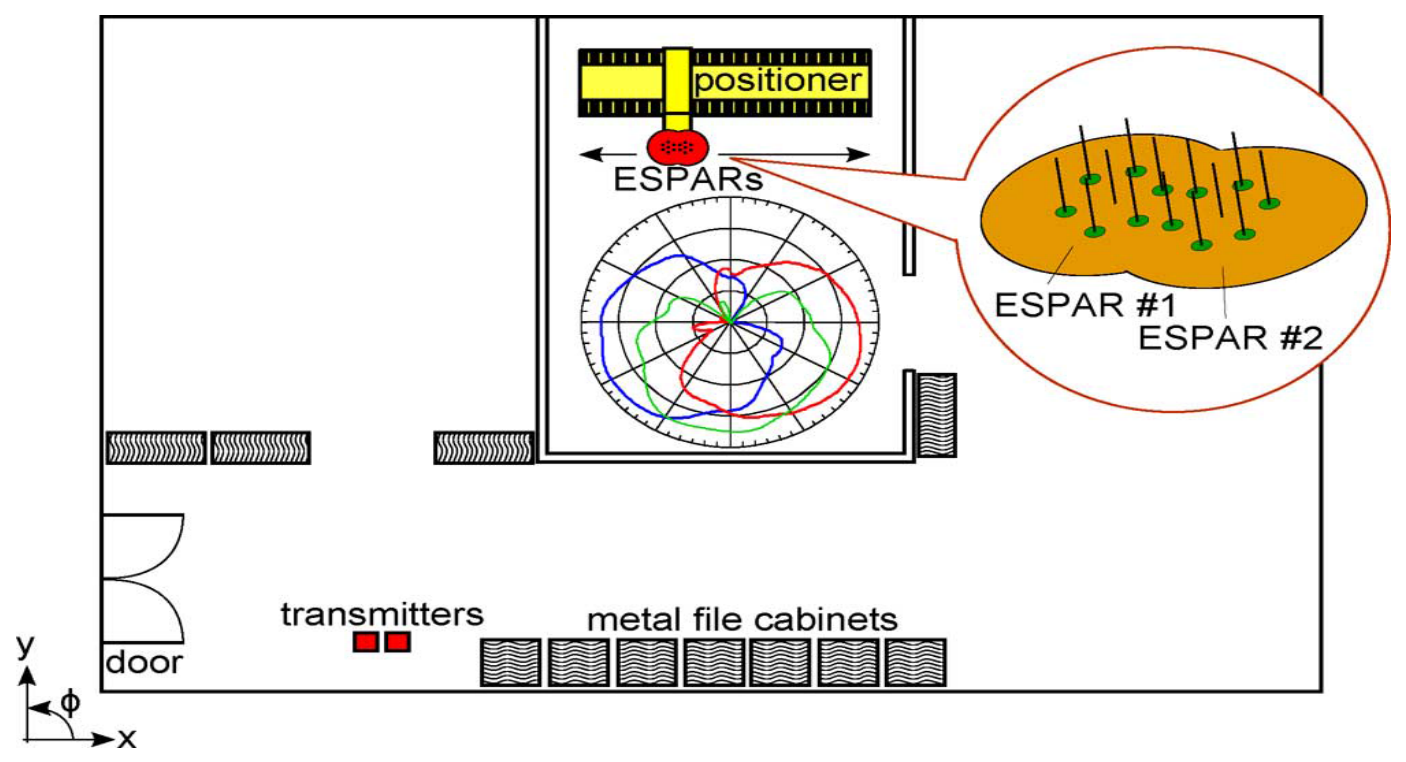

Figure 12. ESPAR patterns and beam angles with respect to test environment [87] 


\subsection{Reconfigurable Antennas for Satellite Application}

The data back bone of the future in metropolitan areas is not much developed, can be overcome by satellite communication system. Recently, Google announced the Loon project that involves the flying balloons used to provide the internet connection everywhere and to every person throughout the world. The flying balloon costs less but its life time is very short whereas the satellite costs more with life time of many years.

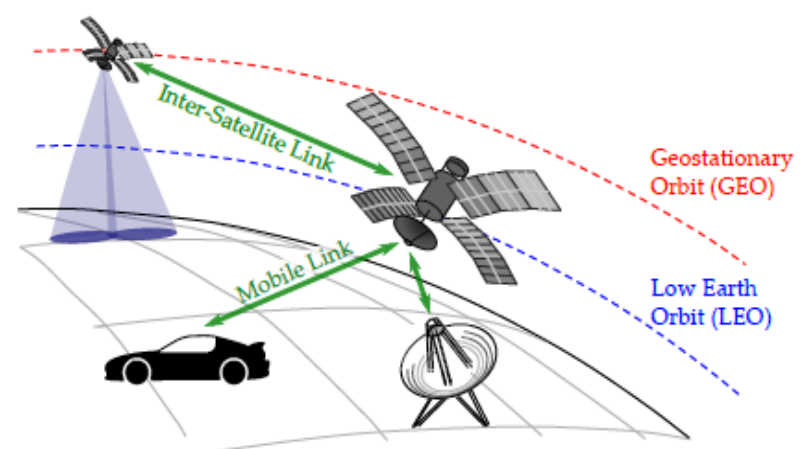

Figure 13. Different application scenarios for beam-steering and forming antennas on a satellite platform [88]

Satellite antenna requires a steerable antenna pattern. It is used for the alignment of the antenna of low-earth-orbit satellite towards a geo-stationary satellite. The different applications for beam-steering and forming antennas on a satellite platform is shown in Figure 13. In case of satellites and balloons both the nodes should be pointed to each other to form a backbone network and provides a networking platform for the users. Figure 13 shows the communication between low-earth orbit with the station i.e. geo-stationary orbit or on ground. Beam steering is required at the nodes of the antenna. It helps in adapting the position of the antenna beam relative to them. It shows low weight and less complexity. Loon project shows highly meshed network that gives high complexity. Mechanical alignment of a conventional antenna is one of the implementation of antenna system with adjustable beam. It is bulk and heavy with drawbacks in terms of cost and reliability.

The microwave components such as phase shifters, tunable filters can overcome the above problems. These components can be realized as: (1) electronically tuned systems (2) mechanically tuned systems (3) functional materials. Basically, the used technologies are based on semiconductors as it has a high-volume market and shows acceptable performance.

Liquid crystals are well known for its display technology shows a mesophase between the solid crystalline and liquid phase. The LC is in a viscous liquid phase showing anisotropic material properties. Liquid crystal can be used for inter-satellite links from LEO to GEO. The LC layer thickness reduces with increase in the frequency, results in a much faster tuning of phase shifter.

\subsection{Reconfigurable Antennas for Biomedical Application}

Linear or circular polarization reconfigurable antennas have many advantages which are enhancement of communication channel, reduction of the multipath interference and polarization coding. In most of the cases, the operating bandwidths are narrow like in case of microstrip patch radiators. Basically, the polarization mismatch occurs in transmitter which can be compensated by polarization diversity in receiver antenna, the deterioration in the signal transmission would be affected by the multi-path distortion and polarization mismatching. Polarization diversity is mostly used in the antennas to improve the quality of the wireless links.

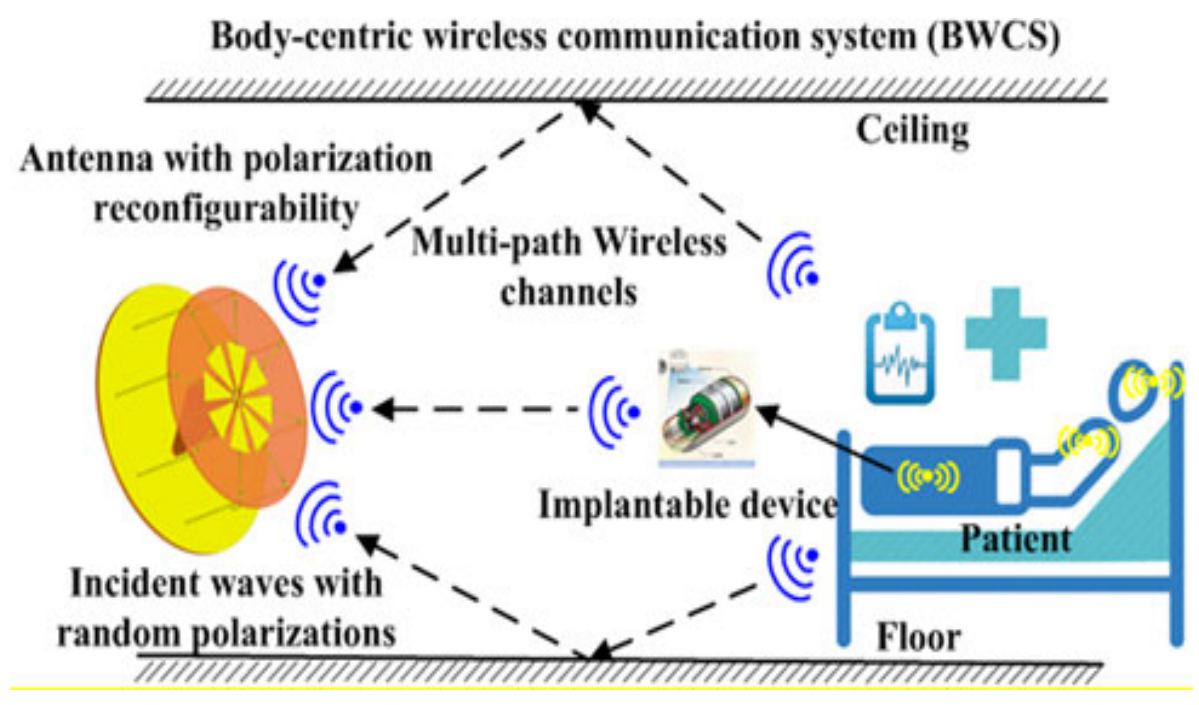

Figure 14. Application diagram of body-centric wireless communication system [91] 
One of the most important examples is body-centric wireless communication system (BWCS) as shown in Figure 14. Inductive link (short range) and far-field Radio-frequency link (long range) is two important approaches of BWCS [89]. The inductive link uses coils and it has advantages of long distance communication and high data rate for information transformation. On-body and Off-body are two wireless devices which are operated in linear mode and can be realized by PIFAs. Due to free movement of human body the orientation of these devices are arbitrary, which may cause multi-path fading. To overcome multi-path fading and polarization mismatch, the external receiver antenna requires features like polarization diversity. The polarization reconfigurability can be achieved using PIN diodes in multi slot antenna [90].

In the multi-slot antenna, pin diodes are used to switch between four polarization modes which are $0^{\circ}, \pm 45^{\circ}$ and $90^{\circ}$ at frequencies between $2.2 \mathrm{GHz}$ and $2.6 \mathrm{GHz}$. The design results in broadside radiation with wide bandwidth and characterized with stable gain for all the modes. In [91], the antenna with polarization diversity minimizes polarization mismatching and induces capability of compensating the effect of multipath distortion, which will able to scan different polarizations. One possible scenario of body-centric wireless communication system (BWCS) with polarization reconfigurable antenna is shown in Figure 10. A patient has several on body and implantable devices to communicate with an external antenna or receiver which is connected with a data processing equipment [91]. Medical doctors can receive various real time information of the patient through body centric wireless communication system (BWCS) network.

\subsubsection{Reconfigurable Wearable Fabric Antenna on upper Arm for Med Radio Band Applications}

System where wireless devices are attached to the human body, On-body and Off-body are most important applications in biological field of communication system with some characteristics such as (i) Miniaturisation (ii) good radiation performance. Low frequency inductive-links transmits in a very short range communication links. One of the best example of this type of communication is Medical Device Radio Communications Service band (MedRadio) that ranges from 401-406 MHz. As the miniaturisation of these antenna dimensions are very difficult to become wearable in human body but due to its flexibility it can be accommodated with any human body. The criteria are satisfied by fabric substrate and one of the flexible antennas is textile antenna. To steer the beam in required directions and to enhance the communication ability we need an antenna with the ability of controlling the beam. A reconfigurable beam steering antenna can enhance the wireless connectivity in on-body applications [92]. By using RF switches we can control the beam. This can be done by distribution of current in the conductive parts of the antenna.

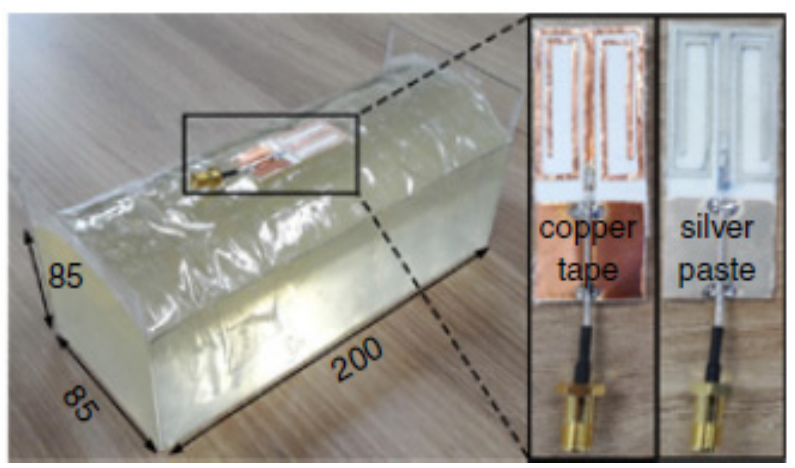

Figure 15. Skin-mimicking Model [92]

A reconfigurable monopole antenna with a spiral structure can act as a wearable on the human upper arm where the spiralling of the monopole antenna can be achieved for antenna miniaturisation. To change the beam of the antenna, two artificial switches are used. The skin-mimicking model can be modelled on the upper arm of the human body which covers the MedRadio band [92]. The position of the antenna on the skin determines the radiation pattern and flexible properties of the antenna communicate with in-/off-body devices. The skin-mimicking model is shown in Figure 15.

Flexible and stretchable electronics have been mainly dominated by applications in large areas displays, energy harvesters, storage devices and implantable electronics, however progress in wearable technologies can generate immediate impact on equality human life [100].

\section{Conclusions}

The paper presented a comprehensive study on different aspects of reconfigurable antennas including their function, classification, reconfiguration techniques, and applications. Reconfigurable antennas were mainly classified into frequency reconfigurable, radiation pattern reconfigurable, polarization reconfigurable, and compound reconfigurable by using electrical, optical, mechanical, and smart material based tunable structures. A detailed comparison between different techniques used to implement reconfigurable antennas was presented. The applications of reconfigurable antennas such as cognitive radio, MIMO systems, satellite communications, and biomedical devices were discussed.

\section{REFERENCES}

[1] M. Riitschlin, V. Sokol, "Reconfigurable antenna simulation, "IEEE Mirow. Mag., pp. 92-101, Dec. 2013.

[2] IEEE Standard Definition of Terms for Antennas, IEEE Standard 145-1993, IEEE Press, New work, 1993. 
[3] S. Nikolaou, N.D. Kingsley, G.E. Ponchak, J. PApapolymerou, and M. M. Tentzeris, "UWB elliptical monopoles with reconfigurable band notch using MEMS switches actuated without bias lines," IEEE Trans. Antennas Propag., vol. 57, no. 8, pp. 2242-2251, Aug. 2009.

[4] E. Erdil, K. Topalli, M. Unlu, O.A. Civi, and T. Akin, "Frequency tunable patch antenna using RF MEMs technology," IEEE Trans. Antennas Propag., vol. 55, no. 4, pp. 1193-1196, Apr. 2007.

[5] C. A. Balanis, Modern Antenna Handbook. Hoboken, NJ, USA: Wiley, 2011.

[6] J.T. Bernhard, Reconfigurable Antennas. San Rafel, CA, USA: Morgan and Claypool, 2007.

[7] E. R. Brown, "RF-MEMS switches for reconfigurable integrated circuits," IEEE Trans. Microw., Theory Tech., vol. 46, no. 11 , pt. 2 , pp. 1868-1880, 1998.

[8] X. s. Yang, B. Z. Wang, S. H. Yeung, Q. Xue, and K.F. Man, "Circularly polarized reconfigurable crossed-yagi patch antenna," IEEE Antennas Propag. Mag., vol. 53, no. 5, pp. 65-80, 2011.

[9] A. Zohur et al, "RF MEMS reconfigurable two-band antenna," IEEE Antennas Wireless Propag. Lett., vol. 12, pp. 72-75, 2013.

[10] G. H. Huff and J. T. Bernhard, "Integration of packaged RF-MEMS switches with radiation pattern reconfigurable square spiral microstrip antennas," IEEE Trans. Antennas Propag. Vol. 54, no. 2, pp. 464-469, Feb. 2006.

[11] B. A. Cetiner, G. R. Crusats, L. Jafre, and N. Biyikli, "RF MEMS integrated frequency reconfigurable anular slot antenna," IEEE Trans. Antennas Propag., vol. 58, no. 3, pp. 626-632, mar. 2010

[12] A. Grau et al., "A dual linearly polarized MEMS-reconfigurable antenna for narrow band MIMO communication systems," IEEE Trans. Antennas Propag., vol. 58, no. 1, pp. 4-16, Jan. 2010.

[13] S. Nikolaou, N. D. Kingsley, G. E. Ponchak, J. Papapolymerou, and M. M. Tenzeris, "UWB elliptical monopoles with a reconfigurable band notch using MEMS switches actuated without bias lines," IEEE Trans. Antennas Propag., vol. 57, no. 8, pp. 2242-2251, Aug. 2009.

[14] E. Erdil, K. Topali, M. D’Unlu, O. A. Civi, and T. Akin, "Frequency tunable patch antenna using RF-MEMS technology," IEEE Trans. Antennas Propag., vol. 55, no. 4, pp. 1193-1196, Apr. 2007.

[15] J. Costatine, Y. Tawk. S. E. Barbin, and C .G. Christodoulou, "Reconfigurable antennas: design and applications," Proc. IEEE, vol. 103, no.3, pp. 424-437, Mar. 2015.

[16] D. Piazza, P. Mookiah, D'anico, and K. Dandekar, "Experimental analysis of pattern and polarization reconfigurable circular patch antennas for MIMO antennas," IEEE Trans. Antennas Propag., vol. 59, no. 5, pp. 2352-2362, 2010

[17] P. Quin, Y. J. Guo, A. R. Weily, and C. Liang, "A pattern reconfigurable U-shaped antenna and its applications in MIMO systems," IEEE Trans. Antennas Propag., vol. 60, no. 2, pt. 1, pp. 516-528, 2012.
[18] L. Hinsz and B. D. Braaten, "A frequency reconfigurable transmitter antenna with autonomous switching capabilities," IEEE Trans. Antennas Propag., vol. 62, no. 7, pp. 3809-3813, 2014.

[19] S. Shelly, J. Costantine, C. G. Christodoulou, D. E. Anagnostou, and J. C. Lyke, "FPGA-controlled switch-reconfigured antenna," IEEE Antennas Wireless Propag. Lett. vol. 9, pp. 355-358, 2010.

[20] S. H. Chen, J. S. Row, and K. L. Wong, "Reconfigurable square-ring patch antenna with pattern diversity," IEEE Trans. Antennas Propag., vol. 55, no. 2, pp. 472-475, Feb. 2007.

[21] S. J. Wu and T. G. Ma, "A wideband slotted bow-tie antenna with reconfigurable CPW to slot line transition for pattern diversity," IEEE Trans. Antennas Propag., vol. 56, no. 2, pp. 327-334, Feb. 2008.

[22] B. Kim et al., "A novel single-feed circular microstrip antenna with reconfigurable polarization capability," IEEE Trans. Antennas Propag., vol. 56, no. 3, pp. 630-638, Mar. 2008.

[23] R. H. Chen and J. S. Row, "Sing-fed microstrip patch antenna with switchable polarization," IEEE Trans. Antennas Propag., vol. 56, no. 4, pp. 922-926, Apr. 2008.

[24] J. Sarrazin, Y. Mahe, S. Avrillon, and S. Toutain, "Pattern reconfigurable cubic antenna," IEEE Trans. Antennas Propag., vol. 57, no. 2, pp. 310-317, Feb. 2009.

[25] J. Perruisseau-Carrier, P. Pardo-Carrera, and P. Miskovsky, "Modelling, design and characterization of a very wide band slot antenna with reconfigurable band rejection," IEEE Trans. Antennas Propag., vol. 58, no. 7, pp. 2218-2226, Jul. 2010.

[26] P. Y. Qin, A. R. Weily, Y. J. Guo, T. S. Bird and C. H. Liang, "Frequency reconfigurable quasi-yagi folded dipole antenna," IEEE Trans. Antennas Propag., vol. 58, no. 8, pp. 2742-2747, Aug. 2010.

[27] Y. Bai, S. Xiao, C. Liu, X. Shuai, and B. Wang, "Design of paterrn reconfigurable antennas based on a two-element dipole array model," IEEE Trans. Antennas Propag., vol. 61, no. 9 , pp. 4867-4871,2013.

[28] S. Onodera, R. Ishikawa, A. Saitou, and K. Honjo, "Multi-band reconfigurable antennas embedded with lumped-element passive components and varactors," in Proc. Asis-Pacific Microw. Conf., 2013, pp. 137-139.

[29] A. H. Ramadan et al., "Tunable filter-antennas for cognitive radio applications,” Progress Electromagn. Res. B, vol. 57, pp. 253-265, 2014.

[30] E. A. Daviu, M. C. Fabres, M. F. Bataller, and A. V. Jimennez, "Active UWB antenna with tunable band-notched behaviour," IEEE Electron. Lett., vol. 43, no. 18, pp. 959-960, Aug. 2007.

[31] W. S. Jeong, S. y. Lee, W.G. Lim, H. Lim, and J. W. Yu, "Tunable band-notched ultra-wideband (UBW) planar monopole antennas using varactor," in Proc. 38th Eur. Microw. Conf. pp. 266-268, 2008.

[32] H. Jiang, M. Patterson, C. Zhang, and G. Subramanyan, "Frequency tunable microstrip patch antenna using ferroelectric thin flim varactor," Proc. Nat. Aerospace 
Electron. Conf., pp. 248-250, Jul. 2009.

[33] S. S. Oh, Y. B. Jung, Y. r. ju, and H. D. Park, "Frequency-tunable open ring microstrip antenna using varactor," in Proc. Int. Conf., Electromagn. Adv. Appl., pp. 624-626, Sep. 2010.

[34] S. L. S. Yang, and A. A. Kishk, and K. F. Lee, "frequency reconfigurable U-slot microstrip patch antenna," IEEE Antennas Wireless Propag. Lett., vol. 7, pp. 127-129, Jan. 2008.

[35] Y. Tawk, J. Costanttine, and C. G. Christodoulou, “A varactor based reconfigurable filternna," IEEE Antennas Wireless Propag., vol. 11, pp. 716-719, 2012.

[36] G. P. Jin, D. L. Zhang, and R. L. Li, "Optically controlled reconfigurable antenna for cognitive radio applications," IET Electron. Lett., vol. 47, no. 17, pp. 948-950, 2011.

[37] Y. Tank, A. R. Albrecht, S. Hemmady, G. Balakrishnan, and C.G. Christodoulou, "Optically pumped frequency reconfigurable antenna design," IEEE Antennas Wireless Propag. Lett., vol. 9, pp. 280-283, Mar. 2010.

[38] Y. Tawk et al., "Demonstration of a cognitive radio front end using an optically pumped reconfigurable antenna system(OPRAS)," IEEE Trans. Antennas Propag., vol. 60, no.2, pt. 2, pp. 1075-1083, 2012.

[39] V. Sathi, N. Ehtheshmi, and J. Nourinia, "Optically tuned frequency reconfigurable microstrip antenna," IEEE Antennas Wireless Propag. Lett., vol. 11, pp. 1018-1020, 2012.

[40] S. Pendharkar, R. K. Shevgaonkar, and A. N. Chandorkar, "Optically controlled frequency-reconfigurable microstrip antenna with low photoconductivity," IEEE Antennas Wireless Propag. Lett., vol. 13, pp. 99-102, 2014.

[41] D. Patron, A. S. daryoush, and K. R. Dandekar, "Optically control of reconfigurable antennas and application to a novel pattern-reconfigurable planar design," IEEE J. lightw. Technol., Early access article, 2014.

[42] D. Rodrigo, L. Jofre, and B. Centiner, "Circular beam-steering reconfigurable antenna with liquid metal plastics," IEEE Trans. Antennas Propag., vol. 60, no. 4, pp. 1796-1802, 2012.

[43] A. Mehdipour et al., "Mechanically reconfigurable antennas using an anisotropic carbon-fibre composite ground," IET Microw. Antennas Propag., vol. 7, no. 13, pp. 1055-1063, 2013.

[44] R. A. Liyakath, A. Takshi, and G. Mumcu, "Multilayer stretchable conductors on polymer substrates for conformal and reconfigure antennas," IEEE antennas Wireless Propag. Lett., vol. 12, pp. 603-606, 2013.

[45] J. Constantine, Y. Tawk, J. Woodland, N. Floam, and C. G. Christodoulou, "Reconfigurable antenna system with a movable ground plane for cognitive radio," IET Microw., Antennas Propag., Early access, 2014.

[46] L. Liu and R. J. Langley, "Liquid crystal tunable microstrip patch antenna," IET Electron. Lett., vol. 44 no. 20, pp. 1179-1180, 2008

[47] C. G. Christodoulou, Y. T. Tawk, S. A. Lane, and S. R. Erwin, "Reconfigurable antennas for wireless and space applications," IEEE Proc. vol. 100, no. 7, Jul. 2012.

[48] "Solid state switches," in Microw. Encyclopedia, http://www.microwaves101.com/encyclopedia/switches_s olidstate.cfm, Nov. 18, 2010.

[49] F. Yang, X. X. Zhang, X. Ye, and Y. Rahmat-samii, "Wide-band E-shaped patch antennas for wireless communications," IEEE Trans. Antennas Propag., vol. 49, no. 7, pp. 1094-1100, Jul. 2001.

[50] H. Rajagopalan, J.M. Kovitz, and Y. Rahmat-Samii, "MEMS reconfigurable optimized E-shaped patch antenna design for congnitive radio," IEEE Trans. Antennas Propag., vol. 62, no. 3, pp. 1056-1064, Mar. 2014.

[51] C.Y. D Sim, T.Y. Han, and Y.J. Liao, " A frequency reconfigurable half annular ring slot antenna design," IEEE Trans. Antennas Propag., vol. 62, no. 6, pp. 3428-3431, Jun. 2014.

[52] Y. Tawk, J. Costantine, A. H. Ramadan, K.Y. Kabalan and C.G. Christodoulou, "A reconfigurable feeding network," in Proc., 8th Eur. Con. Antennas Prog., pp. 1534-1536, 2014.

[53] D. Rodrigo, B.A. Cetiner, and L. Jofre, "Frequency, radiation pattern and polarization reconfigurable antenna using a parasitic pixel layer," IEEE Trans. Antennas Propag., vol. 62, no. 6, pp. 3422-3426, Jun. 2014.

[54] SMV2019 varactors datasheet.

[55] L. Ge and K. M. Luk, "Frequency-reconfigurable low-profile circular monopolar patch antenna,'IEEE Trans. Antennas Propag., vol. 62, no.7, pp. 3443-3449, Jul. 2014.

[56] T. Aboufoul, A. Alomainy,and C.Parini,"Reconfiguring UWB monopole antenna for cognitive radio applications using GaAs FET switches," IEEE Antennas Wireless Propag. Lett., vol. 11, pp. 392-394, 2012.

[57] C. J. Panagamuwa, A. Chauraya, and J. C. Vandaxoglou,' Frequency and beam reconfigurable antenna using photoconductive switches", IEEE Trans. Antennas Propag., vol.54, no. 2, pp. 449-454, Feb. 2006.

[58] Y. Tawk, A. R. Albrecht, S. Hemmady, G.Balakrishnan, and C. G. Christodoulou," Optically Pumped Frequency Reconfigurable Antenna Design”, IEEE Antennas Wireless Propag. Lett. vol.9, pp. 280-283, 2010.

[59] Y. Tawk,J. Costanine,S.E. Barbin,and C.G. Christodoulou,"Integrating Laser Diodes in a reconfigurable antenna system," in Proc. SBMO/IEEE MTT-S Int. Microw. Optoelectron. Conf., Oct.2 011.

[60] S. Jalali Mazlouman, M. Soleimani, A. Mahanfar, C.Menon, and R.G. Vaughan,'Pattern reconfigurable square ring patch antenna actuated by hemispherical dielectric elastomer," Electron. Lett., vol.47, no.3, pp. 164-165, Feb. 2011.

[61] D. M. Pozar and V. Sanchez, "Magnetic tuning of a microstrip antenna on a ferrite substrate," Electron. Lett. , vol. 24, no. 12, pp. 729-731, Jun. 1988.

[62] P. J. Rainville and F. J. Harackewiez," "Magnetic tuning of a microstrip antenna fabricated on a ferrite film," IEEE Microw. Guided Wave Lett., vol. 2, no. 12, pp. 483-485, Dec. 1992. 
[63] R. K. Mishra, S. S. Pattnaik, and N. Das, "Tuning of microstrip antenna on ferrite substrate," IEEE Trans. Antennas Propag., vol. 41, no. 2, pp. 230-233, Feb 1993.

[64] A. Shamim, j. R. Bray, N. Hojjat, and L. Roy, "Ferrite LTCC-based antennas for tunnable SoP applications," IEEE Trans. Compon. Packag. Manuf. Techol., vol. 1, no. 7, pp. 999-1006, Jul. 2011.

[65] L. R. Tan, R. X. Wu, C. Y. Wang, and Y. poo, "Magnetically tunable ferrite loaded SIW antenna," IEEE Antennas Wireless Propag. Lett. , vol. 12, pp. 273-275, Mar. 2013.

[66] H. Jiang, M. Patterson, C. Zhang, and G. Subramanyam, "Frequency agile microstrip patch antenna using ferroelectric thin film varactor technology," in Proc. IEEE Antennas Propag. Soc. Int. Symp. (APSURSI), pp. 1-4, Jun. 2009.

[67] F.A. Miranda, G. Subramanyam, F.W. van Keuls, R.R.Romanofsky, J. D. Warner, and C. H. Muller, "Design and development of ferroelectric tunable microwave components for $\mathrm{Ku}$ and $\mathrm{K}$-band satellite communication systems," IEEE Trans. Microw. Theory Techn., vol. 48, no. 7, pp. 1181-2000, Jul. 2000.

[68] N. Martin, P. Laurent, C. Person, P. Gelin, and F. Huret, "Patch antenna adjustable in frequency using liquid crystal," in Proc. 33rd Eur. Microw. Conf., pp. 699-702, Oct. 2003.

[69] L. Fritzsch, S. Bildik, and R. Jakoby, "Liquid crystal tunable microstrip patch antenna," Electron. Lett., vol. 44, no. 20, pp. 1179-1180, Sep. 2008.

[70] C. Fritzsch, S. Bildik, and R. Jakoboy, "Ka-band frequency tunable microstrip patch antenna," in Proc. IEEE Antennas Propag. Soc. Int. Symp., pp. 1-2, Jul. 2012.

[71] G. H. Huff, P. B. Bahukudumbi, W. N. Everett, A. Beskok, M. A. Bevan, D. Lagoudas and Z. Ounaies, "Microfluidic reconfiguration of antennas," in Proc. Antenna Appl. Symp., Monticello, IL, USA, pp. 241-258, Dec. 2007.

[72] H. T. Buscher, "Electrically controllable liquid artificial dielectric media," IEEE Trans. Microw. Theory Techn., vol. 27, no. 5, pp. 540-545, May 1979.

[73] D. J. Healy, “An examination of the Gamma match,” QST, vol. 57, pp. 11-15, Apr. 1969

[74] M. Konca, P.A. Warr, "A frequency reconfigurable antenna architecture using dielectric fluids," IEEE Trans. Antennas and Propag., vol. 63, no. 12, pp.5280-5286, Dec. 2015.

[75] D. J. Healy, “An examination of the Gamma match,” QST, vol. 57, pp. 11-15, Apr. 1969.

[76] C. A. Balanis, "Broad dipoles and matching techniques," in Antenna Theory: Analysis and Design, 3rd ed. Hoboken, NJ, USA: Wley, 2005.

[77] C. L. Holloway,E.F. Kuester, J. A. Gordon, J. O’Hara, J. Booth, and D. R. Smith, "An overview of theory and applications of metasurfaces: The two-dimensional equivalents of metamatrials," IEEE Antennas propag. Mag., vol. 54, pp. 10-35, 2012.

[78] H. L. Zhu, X. H. Liu, S.W. Cheung and T. I. Yuk, "frequency reconfigurable antenna using metasurface", IEEE Trans. Antennas and Propag., Vol.62, no.1, pp. 80-85, Jan. 2014.

[79] H. L. Zhu, X. H. Liu, S. W. Cheung and T. I. Yuk,” Design of polarization reconfigurable antenna using metasurface", IEEE Trans. Antennas and Propag., vol. 62, no.6, pp. 2891-2896, Jun. 2014

[80] H. L. Zhu, S. W. Cheung and T. I. Yuk, "Mechanically pattern reconfigurable antenna using metasurface", IET Microw. Antennas Propag., vol. 9, iss. 12, pp. 1331-1336, Apr. 2015.

[81] G. M. Rebeiz and J. B. Muldavin, "RF-MEMS switches and switch circuits," IEEE Microw. Mag., vol. 2, no. 2, no. 4, pp. 59-71, Dec. 2001.

[82] I. Gutierrez, E. Hernandez, and E. Melendez, "Design and characterization of integrated varactors for RF applications", New York: Wiely, 2006.

[83] L. Dussopt and G. M. Rebeiz, "Intermodulation distortion and power handling in RF MEMS switches, varactors, and tunable filters," IEEE Trans. Antennas Propag., vol. 51, no. 4, pp. 1247-1256, Apr. 2003.

[84] Skyworks, Inc., Woburn, MA, "SKY13298-360LF: GaAs SP2T switch for ultra-wideband (UWB) 3-8 GHz," Datasheet, 2008 [online].

[85] H. A. Atallah, A. B. Abdel-Rahman, K. Yoshitomi, and R. K. Pokharel, "Compact reconfigurable fitennas using varactors loaded T- shaped and H-shaped resonators for cognitive radio applications," IET Microw. Antennas Propag., vol. 10, Iss. 9, pp. 991-1001, Mar. 2016.

[86] "Handbook of Antenna technologies", Springer Reference, 2016.

[87] Y. Zhou, R. S. Adve, S. V. Hum, "Design and evaluation of pattern reconfigurable antennas for MIMO applications," IEEE Trans. Antennas and Propag., vol. 62, no. 3, pp. 1084-1092.

[88] H. Maune, C. Weickhmann, M. Jost, R. Reese, M. Nickel, C. Fritzsch, and R. Jakoby, "Liquid crystal technology for reconfigurable satcom applications," IEEE Conf., TWIOS, Jan. 2017.

[89] C. R. Liu, Y. X. Guo and S. Q. Xiao, "A review of implantable antennas for wireless biomedical devices," Forum for Electromagnetic Research Methods and Application Technologies (FERMAT), vol 14, pp. 1-11, Mar. 2016.

[90] L. Huitema, H. Wong, W. Lin, and A. Crunteanu, "Reconfigurable multi-slot antenna for biomedical applications," EuCAP, 10th European Conf. on Antennas and Propagation, Apr. 2016.

[91] H. Wong, W. Lin, L. Huitema and E. Arnaud, "Multi polarization reconfigurable antenna for wireless biomedical system," IEEE Trans. Biomedical Circuits and Systems, Early Access Articles, vol. PP, Issue 99, 2017.

[92] S. Kang and C. W. Jung, "Wearable fabric antenna on upper arm for MedRadio band applications with reconfigurable beam capability," Electron. Lett. , vol. 51, pp. 1314-1316, Aug. 2015.

[93] N. Ripin, W. M. A. W. Saidy, A. A. Sulaiman, N. E. A. Rashid and M. F. Hussain, "Miniaturization of microstrip antenna through metamaterial approach," IEEE Student Conference on Research and Development (SCOReD), Putrajaya, Malaysia, 16-17 Dec. 2013. 
[94] G. S. Rajesh, V. Kishore K, V. Kumar, "Multiband microstrip patch antenna using metamaterial for airborne SAR system," IEEE Conf. on SPICES, Feb. 2015.

[95] R. Liu, C. Ji, Z. Zhao, and T. Zhou, "Advanced materials and material genome-review metamaterials: reshape and rethink," Engineering 2015, 1(2): 179-184.

[96] S. B. Glybovski, S. A. Trtyakov, P. A. Belov, Y. S. Kivshar, C. R. Simovski, "Metasurfaces: from microwave to visible," Physics Report 634 (2016) 1-72.

[97] D. Rama Krishna, M. Muthukumar, V. M. Padharipande, "Design and development of rectangular patch antenna array for tri-band applications," Int. J. Electron. Commun.(AEU) 69 (2015) 56-61.

[98] V. Rajeshkumar, S. Raghavan, "A compact metamaterial inspired triple band antenna for wireless/wimax applications,” Int. J. Electron. Commun. (AEU) 69 (2015) 274-280.

[99] B. Anantha, L. Merugu, and P. V. D., "A novel single feed frequency and polarization reconfigurable microstrip patch antenna," Int. J. Commun. (AEU) 72 (2017) 8-16.

[100] J. M. Nassar, J. P. Rojas and A. M. Hussain, "From stretchable to reconfigurable inorganic electronics," Extreme Mechanics Lett. 9 (2016) 245-268. 